\title{
Regional Distributed Energy System Planning: A Case Study of an Ecological Town in China
}

\author{
Juan Chen ${ }^{1 *}$, Bin $\mathbf{L u}^{2}$ \\ ${ }^{1}$ Department of Economic Management, North China Electric Power University, Baoding, China \\ ${ }^{2}$ Department of Computers, North China Electric Power University, Baoding, China
}

Received: 23 April 2018

Accepted: 15 October 2018

\begin{abstract}
The regional distributed energy system is a comprehensive energy utilization system distributed on the user side, which has the characteristics of low carbon, flexibility, complementation, interconnection and so on. It is an important trend of energy system development in China in the future. Firstly, a multi-agent based information physical fusion model for regional distributed energy systems is proposed in this paper. The optimization model of the regional distributed energy system based on decision and capacity optimization is constructed at the macro and micro levels. At the same time, the regional distributed energy system is regarded as a local area "energy Internet" network. Based on graph theory and the layout optimization of an energy station, load center, energy storage center and transmission network, we constructed the "station network" layout optimization model and designed an optimization algorithm that can realize the global layout optimization of energy station, load center, energy storage center and transmission network. Finally, taking an ecological town in central China as an example, we verify the feasibility and validity of the model and method.
\end{abstract}

Keywords: regional distributed energy system, planning, information physical fusion model, decision and capacity optimization, station network layout, ecological towns in China

\section{Introduction}

$2 / 3$ of the world's energy consumption comes from cities, of which building energy consumption accounts for 60 percent of urban energy consumption [1-2], while building operation energy consumption accounts for $85 \%$ of the total building life cycle energy consumption [3]. China's urbanization rate reached $57.35 \%$ in 2016, and the transformation of large areas of old cities and largescale construction of new areas made the cities generally have a compact regional development model, which is

*e-mail: hdjuanchen@163.com population concentration, building concentration and function concentration. China's industrial structure is becoming more advanced and service-oriented, which makes the concentrated areas of urban buildings become the main carriers of energy consumption and greenhouse gas emissions. At the same time, we know that climate warming has led to a significant increase in the total building energy consumption in different climate areas of China, which includes heating energy consumption and air conditioning energy consumption [4]. The environmental problems that appear in stages in the process of industrialization are also being concentrated in China at the present stage [5]. The 106 Annual meeting of the International Energy Association 
released the report "Urban Regional Energy: potential for generating and unleashing potential Energy efficiency New sources," which illustrates the important role of regional energy systems in global energy transformation. However, the "energy Internet," characterized by the deep combination of new energy technology and information technology, is considered to be the only way to realize the sustainable development of energy in the world [6].

The research of the community energy project of the International Energy Agency points out that the energy savings potential generated by the overall optimization of the regional energy system is much greater than the energy-saving effect of the energysaving transformation of a single energy user [7]. The decision and operation optimization of a regional energy system is a kind of unit combination problem [8]. In the case of cooling, heating, power and other requirements determined, and HOMER [9], RETScreen model [10], DER-CAM model [11], MARKAL model [12] and other community energy system technical and economic models use the builtin energy conversion technology library, we can select one or several technologies from the technology bank to form a technical scheme, and compare the various community energy supply systems by model simulation and calculation in order to get a better community energy supply system. From the perspective of the energy supply side, regional energy systems focus on the appropriateness of the application of specific energy technologies [13]. From the perspective of the energy use side, the system is mainly to meet the energy requirements of the system configuration [14]. Community energy planning can be summed up into three "W" problems: when, where and what [15]. In reference 16, the "SMART" principle of energy planning goal in low-carbon urban areas was proposed. Energy planning of green ecological areas is a kind of energy planning on the demand side, which is proposed in reference 17 , and it also constructs the energy microgrid that integrates a power microgrid, thermal microgrid and information network. In reference 18, energy planning of the green ecological region was proposed, which is based on the dynamic prediction and analysis of terminal energy consumption. In reference 19, regional energy planning is discussed in combination with the design and implementation of specific projects. LEED-ND (Leadership in Energy and Environmental Design for Neighborhood Development) in the United States and BREEAM (Building Research Establishment Environmental Assessment Method) Communities in the UK stress that we need to evaluate community energy planning as a whole [20].

In 2012, China issued the "Opinions on Accelerating the Development of Green Buildings" program, which aims to actively promote the development of green eco-urban areas, and this paper also puts forward a comprehensive plan for the energy supply systems of regional buildings such as electric power, gas, heat and so on, as well as the utilization system of renewable energy resources, but the current energy planning system in China is short of planning research on the top-level design of a regional environmental energy system. In the future, however, the Chinese government aims to achieve the goal of energy supply security and energy conservation and emission reduction by planning regional energy systems that are efficient, intelligent and have a high comprehensive utilization rate. In 2016, the Chinese government selected 17 regional integrated energy supply systems in large cities with more developed economies, densely populated populations and high energy demand, as the key demonstration project to promote it, which is based on the integration of cooling, heating, power and gas at the end of energy consumption. Based on the above background, the regional distributed energy system planning is systematically studied in this paper, and the architecture of the regional distributed energy system model and the system-related optimization technology are proposed. It also carries on the simulation research in conjunction with a planned ecological town in China.

\section{Materials and Methods}

\section{Model Construction of Regional Distributed Energy System}

The distributed energy system is opposite centralized energy. It tries to realize the system with the highest resource utilization efficiency, the best economy and the least pollution [21]. The main form of distributed energy systems is CCHP (combined cooling heating and power), which is mainly based on natural gas [22]. The third generation of distributed energy system uses distributed energy to generate electricity, which has many forms of energy output, that is, each building can generate electricity as well as consume it. It is an energy microgrid that can share resources through the energy Internet $[23,24]$. A regional distributed energy system (RDES) is a comprehensive energy utilization system distributed in the user side, which is based on CCHP technology and combines local renewable energy and unused energy, in order to provide energy service systems of cooling, heating and power to users in a certain area at the same time. By the way, it also operates with large power grids and natural gas networks.

\section{General Structure of RDES}

RDES has the following characteristics:

- Complementary low-carbon, that is, the energy sources in the target region such as electricity, natural gas, solar energy, wind energy and biomass energy can be optimized and integrated to form multi-energy complementary, which can make full use of unused energy and reduce carbon emissions. 
- Energy Internet, that is, the system will couple material, energy and information to form a regional energy local area network.

- Flexibility, that is, through the energy Internet, the system of inside and outside bilevel interconnection is established, so that the system has the ability to adjust quickly and adaptively.

- Comprehensive, that is, as an integrated system of energy production, supply and marketing, which realizes the optimal scheduling of energy supply and use and improves the efficiency of comprehensive energy use through the organic coordination and interaction of a multi-energy energy supply system. The general structure of RDES is shown in Fig. 1.

In Fig. 1, the initial energy flow is represented by a fine solid arrow while the dotted arrow represents information flow, the wide dotted arrow indicates power supply, the bold solid line arrow indicates heat supply, and the dotted line arrow indicates cooling. RDES usually consists of four modules, namely primary energy supply module, energy conversion module, energy storage module, and terminal user module. In Fig. 1, the primary energy supply module includes natural gas and various renewable and unused energy sources; The energy conversion module includes energy stations, heat transfer stations, collectors, heat pumps, radiators, etc., which is mainly in the form of secondary energy of cooling, heating and power. The energy storage module includes cooling storage, heating storage and power storage. The end user module includes a plurality of load areas.

\section{Information Physical Fusion Model of RDES Based on MAS}

The stability, efficiency and grade of energy supply may be fluctuated by various energy resource input and energy output of RDES. Coupling energy flow and information flow, the energy Internet provides a train of thought for the stable and efficient operation of RDES. Introducing the idea of an energy bus into the framework of the RDES model not only accords with the typical structure of LAN in the traditional Internet, but also can integrate the application of lowgrade energy, which bring the economies of scale. The Research Foundation on the interaction between information in the energy Internet and physical system is a unified modeling of information system and physical system, which is referred to as cyber physical modeling for short. RDES is a distributed control system that needs a powerful energy management system, and the multi-agent system (MAS) is composed of multiple

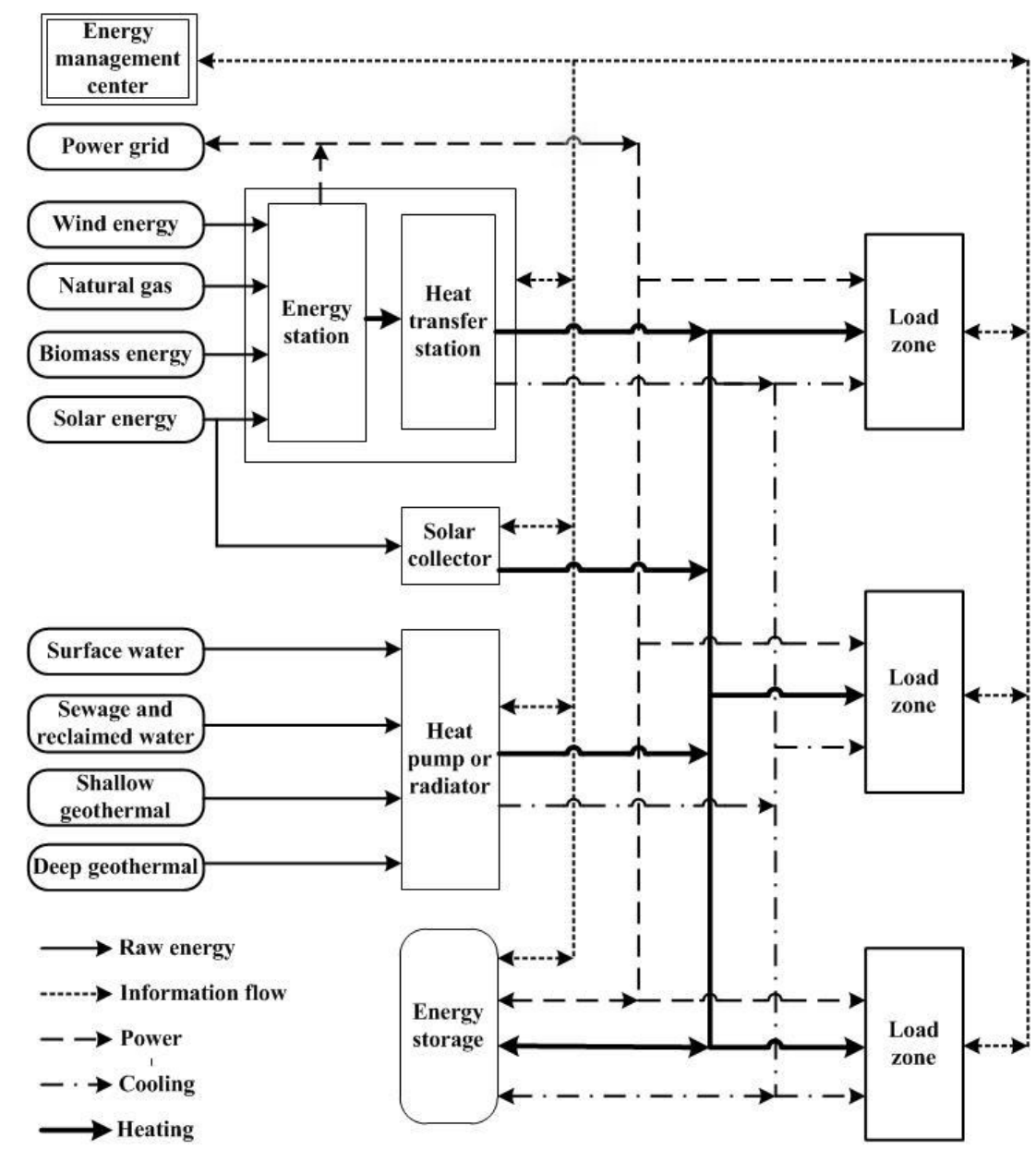

Fig. 1. General structure chart of RDES. 


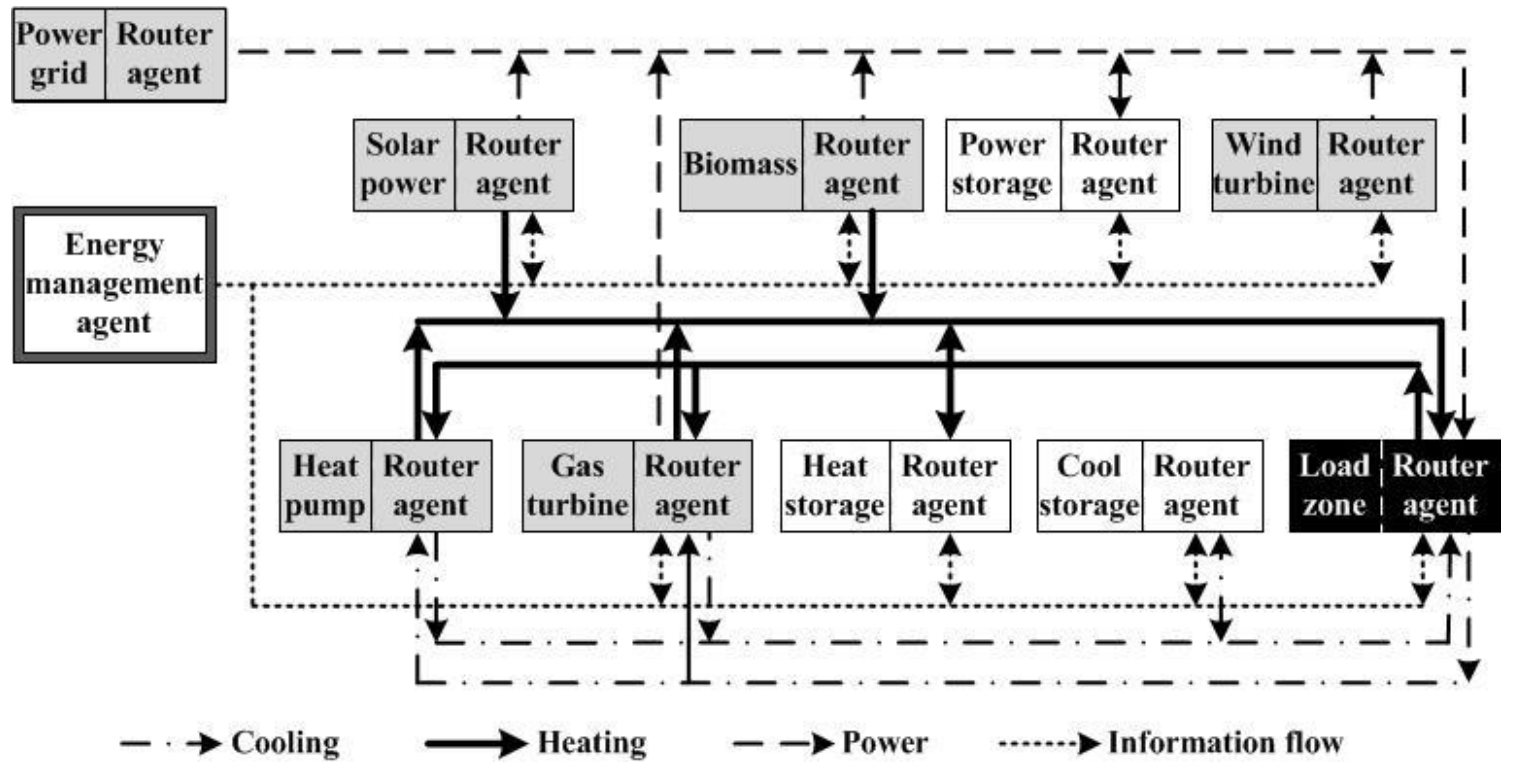

Fig. 2. Architecture diagram of RDES system based on MAS.

loosely coupled agents. The system can adapt to the change of the environment and adjust itself accordingly, and can complete the complex distributed task and solve the problem [25]. MAS is used to ensure the reliability, security and effectiveness of RDES operation. In addition, in the distributed energy system, the supply of heating and cooling cannot meet the needs of users at the same time, so that we can use an energy storage device to store surplus cooling, heating and power, which acts as an energy buffer. Considering the above problems, the RDES model based on MAS is proposed under the CCHP (Fig. 2).

In the RDES model based on MAS, there are two types of agents that are responsible for the future scheduling and running of RDES: energy management agent and routing agent. The information network with routing agent as the core device acts as the coordinated controller of various physical devices (energy supply equipment, energy conversion modules, energy storage equipment and loads, etc.) in the RDES.

\section{RDES Optimization Model Based on Decision and Capacity}

China's energy conservation and emission reduction policy has become a trend that can make full use of renewable and unused energy sources in the energy system. Therefore, in addition to the traditional cogeneration system with natural gas and other energy input, RDES will also gradually increase the variety of renewable distributed energy equipment. In the present situation of distributed energy system in China, we divide the RDES driver into two types (I and II). The former is a cogeneration system with natural gas or biomass as fuel input. The latter refers to a renewable energy system that uses wind and light technologies to generate electricity. In winter, the waste heat from power generation is supplied to regional buildings through heat exchangers. In summer, refrigerated water is supplied to regional buildings by mixed refrigeration, which consists of an absorption refrigeration unit and electric refrigeration unit. When the amount of heat recovered exceeds the demand, the excess part is stored in the heat storage device. When the heat recovered is smaller than the heating and refrigeration demand, the heat storage device will replenish the heat. If the heat still cannot meet the demand, the insufficient part will be replenished by starting the reburning boiler. The superfluous cooling capacity and power quantity can also be stored in the same way as heat storage in order to meet the complex and uneven demands of regional load. In the grid-connected operation mode, the system can be supplemented by a large power grid when there is a shortage of spontaneous electricity. The energy flow diagram of RDES is shown in Fig. 3.

Distributed energy system is a complex energy system. System configuration optimization [26], operation optimization $[27,28]$, configuration and operation integration optimization [29, 30] has been the hotspot of the research. However, most of these optimizations are focused on the system level, and the integrated optimization from up to down, that is, the decision-making to the configuration, is lacking. Therefore, in view of the current situation of energy planning and development environment in China, we propose a two-level optimization of RDES based on decision and system. The decision factors of decision layer are as follows: the basis of regional social development, environmental status, resource endowment, energy policy and the physical characteristics of the key equipment of the system. The capacity optimization layer is determined by the planning objectives, constraints and optimization methods. 


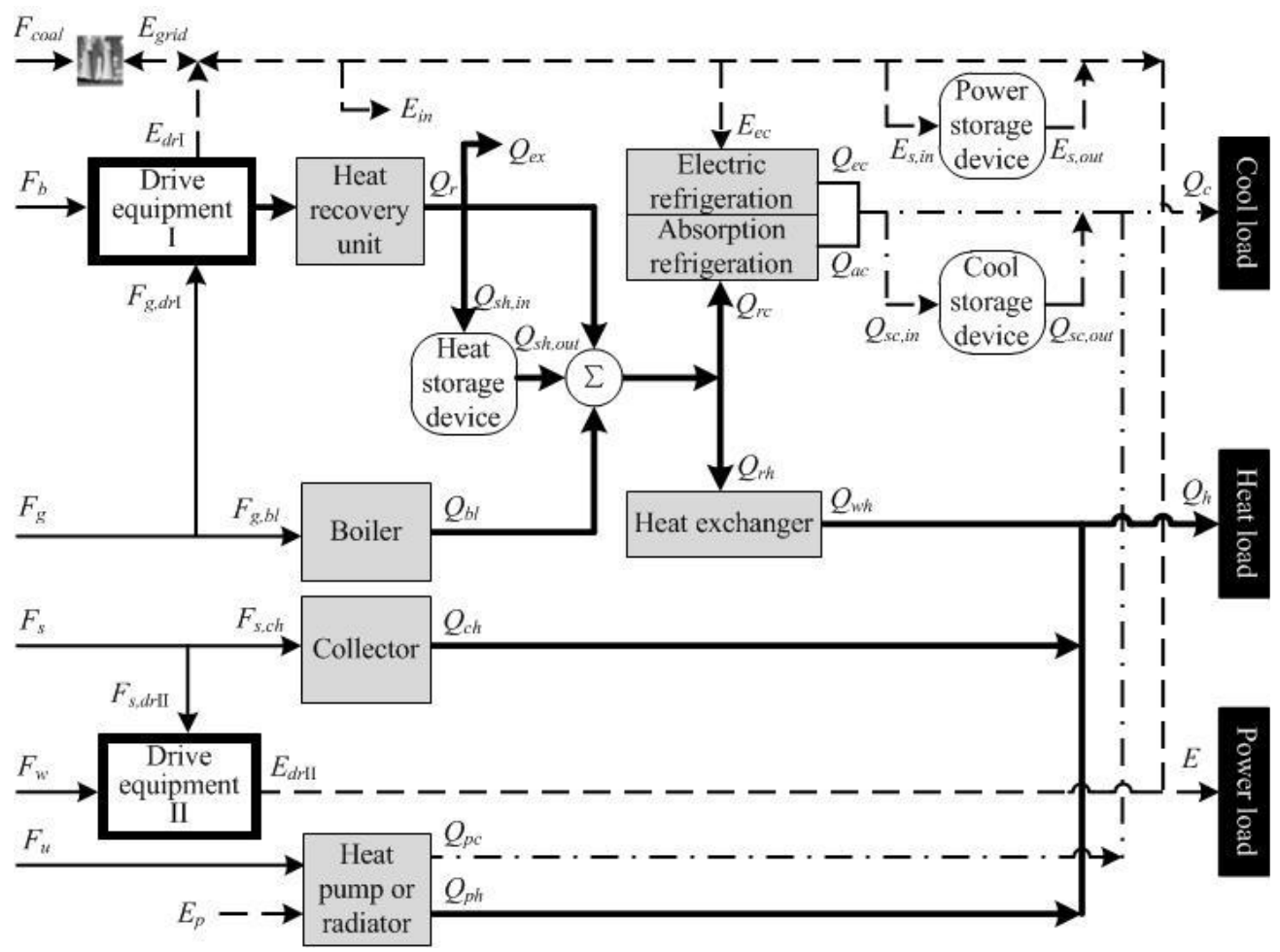

Fig. 3. Schematic diagram of energy flow in RDES.

\section{Decision Optimization of RDES}

The planning and decision of RDES will be influenced by the conditions of regional energy resource endowment, the level of social and economic development, the quality of regional air environment, the preferential encouragement policy and the physical characteristics of energy system equipment. First of all, we should increase the use of renewable energy in the region as much as possible in system planning and improve the reverse distribution between energy resource endowment and energy demand in China, which play a complementary role in the utilization of energy resources. Secondly, although a distributed energy system shows a great advantage in environmental protection, it also has a higher investment cost than other systems. Because of the different degrees of economic development in China, the bearing capacity, demand type, dependence degree and consumption quality improvement of energy consumption and investment in terms of demands and wishes are different. Thirdly, the urgency degree of energy-saving and emission-reduction, and the demand of constructing an environmentally friendly energy system show a different level in the result of the obvious regional difference of air quality in China. Fourthly, nowadays local governments in China have formulated incentive policies for distributed energy systems, but have a difference in the mode and intensity of preferential treatment. Therefore, the planning of RDES not only needs to select suitable equipment, but also consider the factors of social, economic and environmental, according to the rules (IF.. THEN ...) and intelligent reasoning techniques by expert empirical knowledge, so realizing the optimal decision of the system.

\section{Capacity Optimization of RDES}

RDES system optimization layer constructs the capacity optimization model, which is determined by objective factor, constraint factor and algorithm factor, and solves the problem of system capacity configuration under multi-objective.

A. Objective factor

Under the double pressure of rapid adjustment of energy consumption structure and environmental pollution in China, the economy and environmental protection of the system configuration have attracted much attention. The optimal configuration of the system aims at economic and environmental protection, which is in line with the development status and future trend of the distributed energy system in China. C represents economic costs and $\mathrm{M}$ means carbon emissions, then the optimization objective can be expressed as:

$$
\min \{C, M\}
$$

In the formula, the economic costs $C$ mainly include initial investment cost, annual energy consumption cost and annual maintenance cost.

$$
C=C_{o} \frac{r(1+r)^{L}}{(1+r)^{L}-1}+C_{f}+C_{m}
$$


In the formula, $C_{o}$ represents the investment costs at the beginning of the year; $C_{f}$ represents the cost of annual energy consumption; $C_{m}$ represents the cost of annual maintenance; $r$ represents annual discount rate; and $L$ represents project life. $C_{o}, C_{f}, \mathrm{Cm}$ can be expressed as:

$$
C_{o}=\sum_{k=1}^{N} V_{k} C_{k}
$$

...where $V_{k}$ represents the capacity of device $k, k \in\{$ Type I driver equipment $\} ; C_{k}$ represents the investment cost per unit capacity of equipment $k$; and $N$ is the total equipment of energy supply system.

$C_{f}=\sum_{d=1}^{365} \sum_{h=1}^{24}\left(F_{d h, g} C_{g}+F_{d h, b} C_{b}+E_{d h, g r i d} C_{e}-E_{d h, s, d r \mathrm{II}} C_{s, d r \mathrm{II}}\right)$

...where $C_{e}$ is the electricity price of large power grid; $C_{g}$ represents the price of natural gas; $C_{b}$ represents the price of biomass; $C_{s, d r I I}$ represents subsidies for renewable energy generation; and $E_{\text {grid }}$ represents the amount of electricity exchanged between the regional energy Internet and large power grids, $E_{\text {grid }}>0$ means buying electricity from it, $E_{\text {grid }}<0$ means selling electricity to it, which will generate revenue to offset some of the economic costs.

$$
C_{m}=\left(\mu_{1}+\mu_{2}\right) C_{o}
$$

...where $C_{m}$ mainly refers to labour costs and maintenance costs incurred, in the formula, $\mu_{1}$ is the proportional coefficient of labor cost and $\mu_{2}$ is the proportional coefficient of maintenance cost.

Although the environmental performance of RDES has been greatly enhanced, there are still some direct emissions and indirect emissions, that is, direct emissions from combustion running in a cogeneration system, and indirect emissions from electricity purchased from the grid. Considering the above two carbon emissions, systemic carbon emissions $M$ can be expressed as:

$$
M=\sum_{d=1}^{365} \sum_{h=1}^{24}\left(F_{d h, g} \alpha_{g}+F_{d h, b} \alpha_{b}+F_{d h, \text { coal }} \alpha_{c o a l}\right)
$$

...where $\alpha_{g}$ is the carbon dioxide emission coefficient of natural gas; $a_{b}$ represents the carbon dioxide emission factor of renewable combustions; $\alpha_{\text {coal }}$ is the carbon dioxide emission coefficient of coal; and $F_{\text {coal }}$ is the coal consumption of a thermal power plant, which corresponds to the power consumption of a large power grid.

\section{B. Constraint factors}

There are two types of constraint factors for capacity planning of RDES: the balance constraint between input and output of the single device itself, and overall load demand constraint for the energy flow balance of the system.

1) Constraints for device running.

The CCHP system

CCHP power generation quantity with natural gas as the input fuel can be expressed as:

$$
E_{g, d r \mathrm{I}}=F_{g, d r \mathrm{I}} \eta_{g e}, 0 \leq E_{g, d r \mathrm{I}} \leq V_{g, d r \mathrm{I}} \cdot 1 \mathrm{~h}
$$

...where $E_{\text {g.drI }}$ represents power generation quantity of driving equipment, $\mathrm{kW} \bullet \mathrm{h} ; F_{g . d r I}$ represents the consumption quantity of natural gas as primary energy, $\mathrm{kW} \cdot \mathrm{h} ; \eta_{g e}$ represents the generation efficiency of driving equipment; and $V_{g . d r I}$ represents the capacity of driving equipment, $\mathrm{kW}$. In addition to natural gas as fuel input, the CCHP can also accept other fuel inputs like biomass. After system power generation, the waste heat with different forms and different qualities will be generated, and the waste heat recycling and utilization device can be used to realize the cascade utilization of energy. The heat recycled by the heat recycling unit can be expressed as:

$Q_{r}=\left\{F_{g, d r I}\left(1-\eta_{g e}\right)+F_{b}\left(1-\eta_{b e}\right)\right\} \eta_{r}, 0 \leq Q_{r} \leq V_{r} \cdot 1 \mathrm{~h}$

...where $Q_{r}$ represents the heat recycled from the heat recycling unit, $\mathrm{kW} \cdot \mathrm{h} ; \eta_{r}$ represents the efficiency of heat recycling unit; and $V_{r}$ represents the capacity of heat recycling unit, $\mathrm{kW}$. In winter, the waste heat after power generation will be exchanged to meet the heat load demand in the region by heat exchanger. In summer, waste heat after power generation is used to create chilled water through a hybrid refrigeration system consisting of an absorption refrigeration unit and an electric refrigeration unit to meet the regional cooling load demand. Heat output by exchanger can be expressed as:

$$
Q_{w h}=Q_{r h} \eta_{h}, 0 \leq Q_{\mathrm{wh}} \leq V_{w h} \cdot 1 \mathrm{~h}
$$

...where $Q_{w h}$ represents the heat output by the heat exchanger, $\mathrm{kW} \bullet \mathrm{h} ; Q_{r h}$ represents the heat into the heat exchanger, $\mathrm{kW} \bullet \mathrm{h} ; \eta_{h}$ represents the efficiency of heat exchanger; and $V_{w h}$ represents the capacity of heat exchanger, $\mathrm{kW}$. The cooling quantity of the absorption chiller after heat recycling can be expressed as:

$$
Q_{a c}=Q_{r c} C O P_{a c}, 0 \leq Q_{\mathrm{ac}} \leq V_{a c} \cdot 1 \mathrm{~h}
$$

...where $Q_{a c}$ represents the refrigerating quantity output by absorption cooler, $\mathrm{kW} \bullet \mathrm{h} ; Q_{r c}$ represents the heat absorbed by absorption cooler, $\mathrm{kW} \bullet \mathrm{h} ; C O P_{a c}$ represents the efficiency of absorption cooler; and $V_{a c}^{a c}$ represents 
the capacity of absorption cooler, $\mathrm{kW}$. The refrigerating quantity of an electric cooler unit can be expressed as:

$$
Q_{e c}=E_{e c} C O P_{e c}, 0 \leq Q_{e c} \leq V_{e c} \cdot 1 \mathrm{~h}
$$

...where $Q_{e c}$ represents the refrigerating quantity output by an electric cooler unit, $\mathrm{kW} \cdot \mathrm{h} ; E_{e c}$ represents power consumption of electric cooler unit, $\mathrm{kW} \cdot \mathrm{h}$; $C O P_{e c}$ represents the efficiency of electric cooler; and $V_{a c}$ represents the capacity of electric cooler, $\mathrm{kW}$. It is very important to use the heat storage devices and the supplementary firing burner unit to realize the efficient utility of energy. The working process of the heat storage devices can be expressed as:

$$
\begin{aligned}
& Q_{d(h+1), s h}=\eta_{s h} Q_{d h, s h}+B_{d h, s h, i n} Q_{d h, s h, i n}- \\
& \text { - } B_{d h, s h, o u t} Q_{d h, \text { sh,out }} \\
& Q_{(d+1) 1, s h}=\eta_{s h} Q_{d 24, s h}+B_{d h, s h, i n} Q_{d 24, s h, i n}- \\
& \text { - } B_{d h, \text { sh,out }} Q_{d 24, \text { sh,out }}, 0 \leq Q_{\text {sh }} \leq V_{\text {sh }} \cdot 1 \mathrm{~h}
\end{aligned}
$$

...where $d$ represents some one day, $d=1,2, \ldots, 364 ; h$ represents hour, $h=1,2, \ldots, 23 ; Q_{s h}$ represents the heat stored in the heat storage device, $\mathrm{kW} \bullet \mathrm{h} ; Q_{\text {sh }}{ }_{\text {in }}$ represents heat into the heat storage device, $\mathrm{kW} \bullet \mathrm{h} ; Q_{\text {sh, out }}$ represents heat output by heat storage device, $\mathrm{kW} \cdot \mathrm{h} ; \eta_{s h}$ represents the efficiency of heat storage device; $V_{s h}$ represents the capacity of heat storage device, $\mathrm{kW}$; and $B_{s h \text {,in }}$ and $B_{\text {sh,out }}$ represent the heat storage sigh and heat release sign respectively, with 0 denoting close and 1 denoting open, and satisfy:

$$
B_{\text {sh,in }}+B_{\text {sh,out }} \leq 1
$$

The heat supplied by gas fired boiler can be calculated by:

$$
Q_{b l}=F_{g, b l} \eta_{b l}, 0 \leq Q_{b l} \leq V_{b l} \cdot 1 \mathrm{~h}
$$

...where $Q_{b l}$ represents the heat output by gas-fired boiler, $\mathrm{kW} \cdot \mathrm{h} ; F_{g, b l}$ represents energy consumption of gas-fired boiler, $\mathrm{kW} \cdot \mathrm{h} ; \eta_{b l}$ represents the efficiency of gas-fired boiler; and $V_{b l}$ represents the capacity of gas fired boiler, $\mathrm{kW}$. In addition, in the auxiliary system of the CCHP, the fan, pump and other equipment will also consume a certain amount of electricity, that is, the internal power consumption can be expressed as:

$$
E_{\text {in }}= \begin{cases}0.26 \lambda_{c}\left(E_{e c}+0.11 Q_{w h}\right), & \text { inheating } \\ 0.26 \lambda_{h}\left(E_{e c}+0.11 Q_{w h}\right), & \text { incooling }\end{cases}
$$

...where $E_{\text {in }}$ represents the internal power consumption of the CCHP, $\mathrm{kW} \bullet \mathrm{h} ; \lambda_{c}$ represents the internal power consumption coefficient in refrigeration mode; and $\lambda_{h}$ represents internal power consumption coefficient in heating mode. The heat balance constraint of the CCHP can be expressed as:
$Q_{r}+Q_{b l}+B_{\text {sh,out }} Q_{\text {sh,out }}=Q_{r c}+Q_{r h}+Q_{e x}+B_{s h, \text { in }} Q_{s h, \text { in }}$

...where $Q_{e x}$ represents the afterheat emitted into the atmosphere, $\mathrm{kW} \bullet \mathrm{h}$. The gas consumption of the CCHP can be expressed as:

This is an example of an equation:

$$
F_{g}=F_{g, d r \mathrm{I}}+F_{g, b l}
$$

(2) Operation constraint of wind turbine [31]

$$
\begin{gathered}
E_{w, d r \mathrm{II}}=\int_{\Delta t} P_{\mathrm{WT}} d t, 0 \leq E_{w, d r \mathrm{II}} \leq V_{\mathrm{WT}} \cdot 1 \mathrm{~h} \\
P_{\mathrm{WT}}=\left\{\begin{array}{cc}
0 & v \leq v_{i}, v \geq v_{o} \\
\frac{v^{3}-v_{i}^{3}}{v_{N}^{3}-v_{i}^{3}} V_{\mathrm{WT}}, & v_{i} \leq v \leq v_{N} \\
V_{\mathrm{WT}} & v_{N} \leq v \leq v_{o}
\end{array}\right.
\end{gathered}
$$

...where $E_{w, d r I I}$ represents the power generation of the wind power system, $\mathrm{kW} \bullet \mathrm{h} ; P_{W T}$ represents the output power of the wind power system, $\mathrm{kW} ; V_{W T}$ represents the rated output power of the wind power system, $\mathrm{kW}$; $v_{i}$ represents cut-in wind speed; and $v_{N}$ represents rated wind speed.

(3) Operational constraint of solar generation [32]

$$
\begin{gathered}
E_{s, d r \mathrm{II}}=\int_{\Delta t} P_{\mathrm{PV}} d t, 0 \leq E_{s, d r \mathrm{II}} \leq V_{\mathrm{PV} \cdot 1 \mathrm{~h}} \\
P_{\mathrm{PV}}=\eta_{\mathrm{PV}} V_{\mathrm{PV}} \frac{I}{I_{\mathrm{STC}}}
\end{gathered}
$$

...where $E_{s, d r I I}$ represents the power generation of solar generator system, $\mathrm{kW} \cdot \mathrm{h}$ and $\Delta \mathrm{t}$ represents interval of time. $P_{P V}$ represents output power of solar generator system, kW; $I$ represents solar irradiance, $\mathrm{W} / \mathrm{m}^{2} ; I_{\text {STC }}$ represents solar irradiance under STC, W/m²; $\eta_{P V}$ represents photoelectric conversion efficiency of solar energy; and $V_{P V}$ represents the capacity of solar generator system, kW. In RDES, we not only use solar power, but also use a solar collector to make use of light and heat. The heat provided by the solar collector system can be expressed as:

$$
Q_{c h}=\frac{\eta_{c h} V_{c h}}{I_{\mathrm{STC}}} \int_{\Delta t} I d t, 0 \leq Q_{c h} \leq V_{c h} \cdot 1 \mathrm{~h}
$$

...where $Q_{c h}$ represents the heat provided by a solar collector system, $\mathrm{kW} \bullet \mathrm{h} ; \eta_{c h}$ represents the efficiency of solar photothermal conversion; and $V_{c h}$ represents the capacity of solar collector system, $\mathrm{kW}$.

(4) Model of heat pump system.

This is an example of an equation: The heating (cooling) quantity produced by the heat pump system can be expressed as [33]: 


$$
\begin{aligned}
& Q_{p h}=E_{p} \operatorname{COP}_{p}, 0 \leq Q_{p h} \leq V_{p} \cdot 1 \mathrm{~h} \\
& Q_{p c}=E_{p} \operatorname{COP}_{p}, 0 \leq Q_{p h} \leq V_{p} \cdot 1 \mathrm{~h}
\end{aligned}
$$

...where $Q_{p h}\left(Q_{p c}\right)$ represents heating (cooling) quantity produced by the heat pump system, $\mathrm{kW} \bullet \mathrm{h}$, but they can't be provided at the same time; $E_{p}$ represents the power consumption of the heat pump system; $C O P$ represents the efficiency of the heat pump system; and $V_{p}^{p}$ represents the capacity of the heat pump system, $\mathrm{kW}$.

(5) Operational constraints of energy storage device.

1. Constraints of power storage device.

Due to the instability of renewable energy output, an energy storage device has become an important configuration for improving the power quality of renewable generation system, maintaining system stability and avoiding peak load. Assuming that the capacity $E_{s}(\mathrm{t}+1)$ of battery energy storage unit model at $(\mathrm{t}+1)$ time is related to the discharge capacity $E_{s}(\mathrm{~T})$ of $\mathrm{t}$ period, the charging and discharging model of battery energy storage unit can be expressed as [34]:

$$
\begin{aligned}
& E_{s}(t+1)=\left\{\begin{array}{l}
E_{s}(t)+\Delta t \frac{P_{c, t}}{\eta_{c}}, \text { incharging } \\
E_{s}(t)-\Delta t \frac{P_{d, t}}{\eta_{d}}, \text { indischarging }
\end{array}\right. \\
& P_{c}^{\min } \leq P_{c, t} \leq P_{c}^{\max }, P_{d}^{\min } \leq P_{d, t} \leq P_{d}^{\max }, \\
& 0 \leq E_{s} \leq V_{s} \cdot 1 h
\end{aligned}
$$

...where $P_{c . t}$ represents the charging power of the time t phase, $\mathrm{kW} ; P_{d, t}$ represents the discharging power of the time $\mathrm{t}$ phase, $\mathrm{kW} ; E_{s}(\mathrm{t})$ represents the amount of electricity at $\mathrm{t}$ time, $\mathrm{kW} \cdot \mathrm{h} ; V_{s}$ represents the capacity of power storage device, $\mathrm{kW} ; \eta_{c}$ represents charging efficiency; and $\eta_{d}$ represents discharging efficiency. The storage power and release power of the storage device can be represented as:

$$
\begin{aligned}
& E_{s, \text { in }}=\frac{1}{\eta_{c}} \int_{\Delta t} P_{c, t} d t \\
& E_{s, \text { out }}=\frac{1}{\eta_{d}} \int_{\Delta t} P_{d, t} d t
\end{aligned}
$$

...where $E_{s^{\prime} \text { in }}$ represents the amount of electricity stored in an electric storage device within $\Delta \mathrm{t}$ time, $\mathrm{kW} \cdot \mathrm{h}$; and $E_{s, \text { out }}$ represents the amount of electricity discharged by electric storage device within $\Delta \mathrm{t}$ time, $\mathrm{kW} \cdot \mathrm{h}$.

2. Constraints of cooling storage device

The working process of the cooling storage device can be expressed as $[35,36]$ :

$$
\begin{aligned}
& Q_{d(h+1), s c}=\eta_{s c} Q_{d h, s c}+B_{d h, s c, i n} Q_{d h, s c, i n}- \\
& -B_{d h, s c, \text { out }} Q_{d h, s c, \text { out }} \\
& Q_{(d+1) 1, s c}=\eta_{s c} Q_{d 24, s c}+B_{d h, s c, i n} Q_{d 24, s c, i n}- \\
& -B_{d h, s c, \text { out }} Q_{d 24, s c, \text { out }} \\
& 0 \leq Q_{s c} \leq V_{s c} \cdot 1 h
\end{aligned}
$$

...where $Q_{s c}$ represents cooling amount stored in storage device, $\mathrm{kW} \cdot \mathrm{h} ; Q_{\text {sc.in }}$ represents cooling amount into storage device, $\mathrm{kW} \cdot \mathrm{h} ; Q_{\text {scout }}$ represents cooling amount output by storage device, $\mathrm{kW} \cdot \mathrm{h} ; \eta_{s c}$ represents the efficiency of cooling storage device; $V_{s c}$ represents the capacity of cooling storage device, $\mathrm{kW}$; and $B_{s c, i n}$ and $B_{s c, o u t}$ represent the cooling storage sign and release sign ( 0 denotes close, 1 denotes open) and satisfy:

$$
B_{s c, \text { in }}+B_{s c, \text { out }} \leq 1
$$

\section{2) Constraints of system energy balance.}

RDES capacity planning not only needs to consider the balance constraints between the input and output of the unit equipment, but also needs to consider whether the overall load of the energy flow balance in the system meets its constraints. The operating constraint conditions for balance of cooling, heating and power respectively in the system are shown in Fig. 4.

\section{Algorithm factor}

The capacity optimization methods of energy systems include linear programming, mixed integer nonlinear programming, genetic algorithm, particle swarm optimization, maximum rectangle method and so on. Because there is a certain contradiction between the optimization objectives, there is not an "absolute optimal solution" that makes all the objectives reach the optimal, but a "Pareto optimal" solution set. RDES capacity optimization will adopt NSGA-II genetic algorithm to maintain the independence of each optimization objective, and then improve the convergence of the algorithm through the optimal retention mechanism. Finally, the Pareto optimal solution of capacity optimization is obtained. K. Deb et al. [37] proposed an undominated sorting genetic algorithm based on elitist strategy. On the basis of ensuring the diversity of the population, the independence between the optimization objectives should be maintained to the maximum extent, and the convergence of the algorithm is improved through the optimal retention mechanism, which makes the global optimization ability stronger. This makes NSGA-II widely used in multi-objective optimization and solution in various fields [38, 39]. RDES's algorithm solution flow is shown in Fig. 5.

\section{Optimized Layout of "Station-Network" in RDES}

RDES consists of energy stations, energy storage centers, distribution networks and load centers - all of which are embedded in the region. The energy station is responsible for the production and output of energy. The users of the demand for the cooling, heating and power load are scattered in each functional building in the region, and the connection between the energy station and the user is realized by the pipe network. The buildings in the area have been well laid out before the energy system planning. How to select the site of the energy station and the layout of the pipeline 
a)

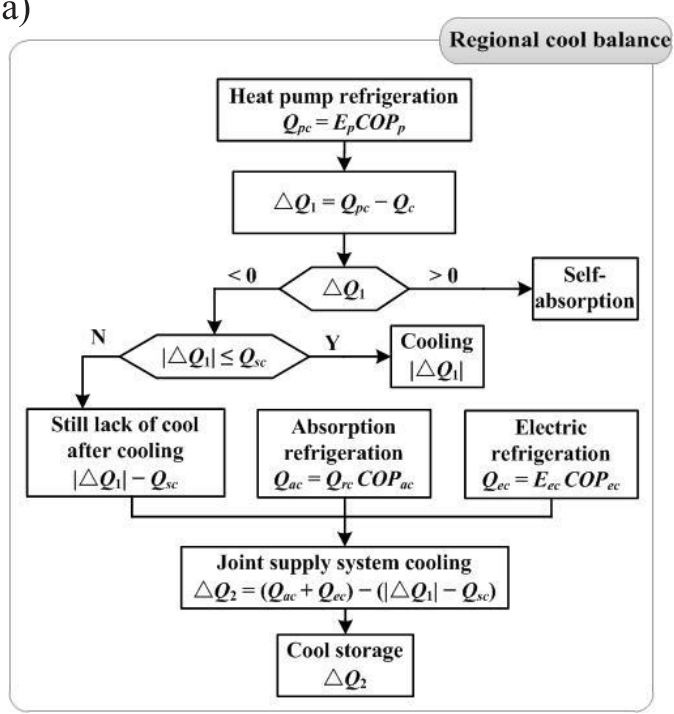

b)

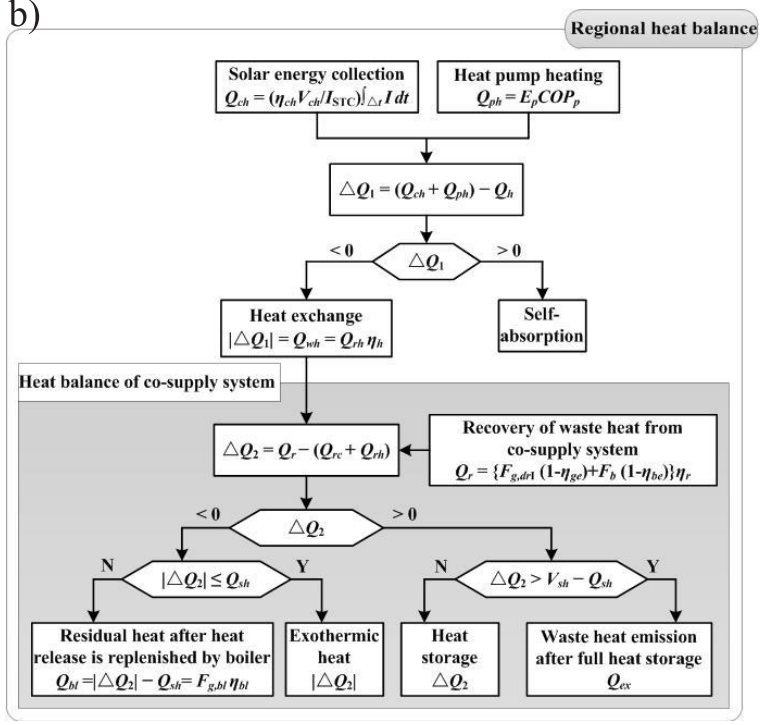

c)

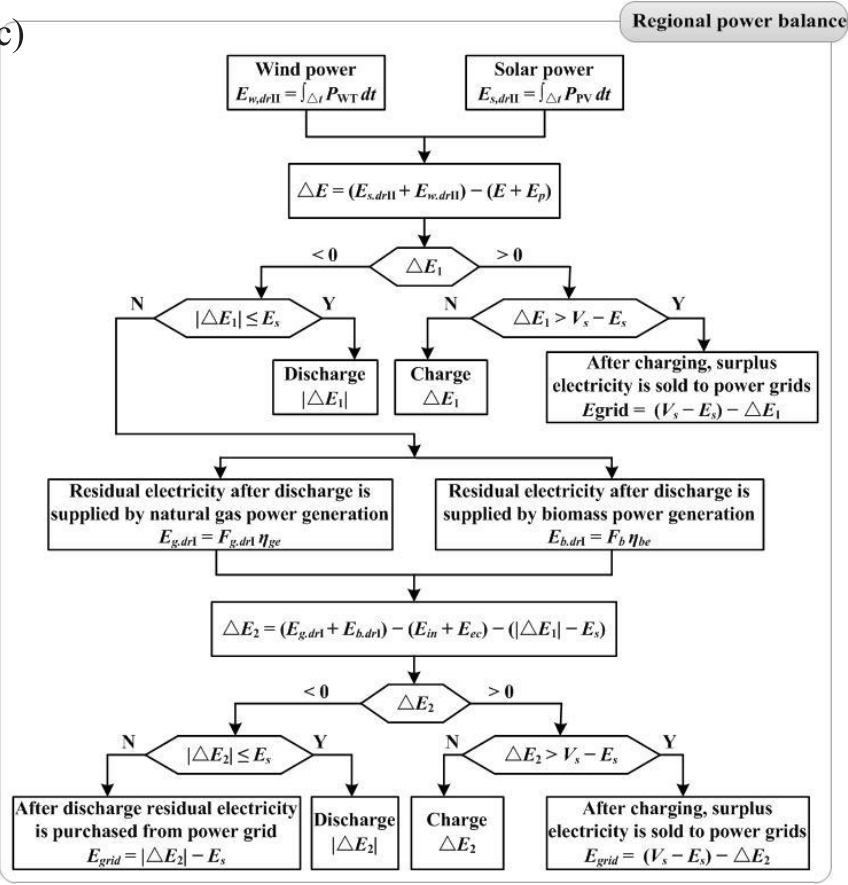

Fig. 4. Operational strategy of cooling, heating and power balance of RDES: a) Cool balance operating constraints, b) Heating balance operating constraints, c) Power balance operating constraints.

network in the area is an important process of RDES planning. In reference 40 , the energy center planning sites are selected by the predefined alternative energy supply center and the distributed energy technology type. In reference 41 , the problems of the quantity of distributed energy supply points and the optimal layout of pipeline network are solved by establishing bilevel programming. Through a distributed productivity system based on natural gas, reference 42 studies the synergistic relationship between the thickness of insulation layer and transportation distance of cooling and heating logistics pipeline. The existing research lacks the integrated optimization layout of "stationnetwork" of the distributed energy system. Based on the known regional load and capacity optimization result of the energy supply system, this paper attempts to realize the optimal cooperative layout of "station-network" in RDES, which is based on graph theory.

\section{'Station-network' map of RDES}

According to graph theory, the distributed energy stations, energy storage centers and load areas involved in RDES can be regarded as the nodes of the graph, and all the conveying pipe networks form the edges of the graph, so that the cooling, heating and power in the network can be transferred and distributed flexibly. RDES energy station and network map (abbreviated as "station-network") can be recorded as $G=(V, E, W)$, with $V$ representing a set of vertices, $E$ representing 


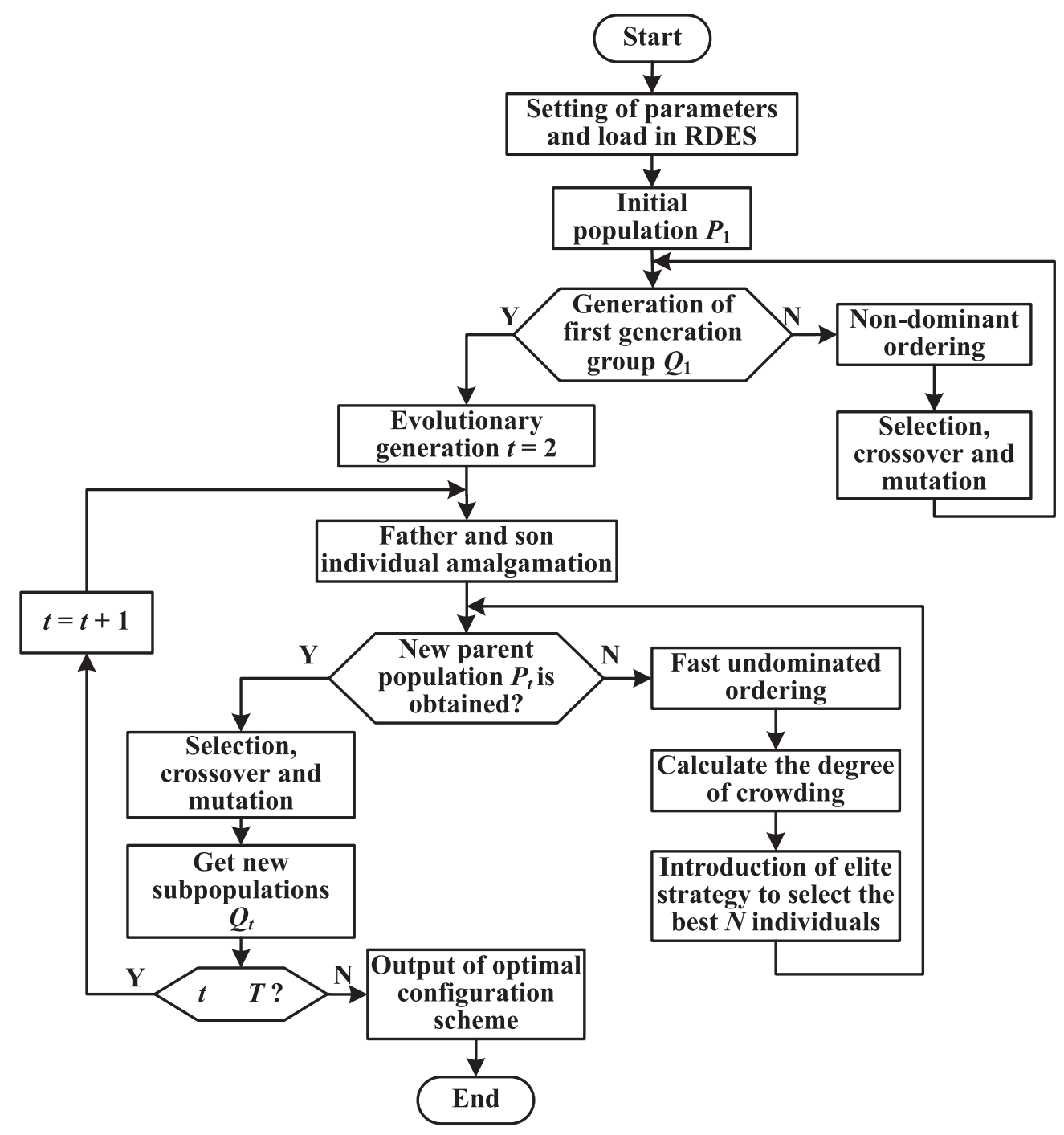

Fig. 5. Flow chart of NSGA-II multi-objective genetic algorithm.

the set of edges, and $W$ representing the set of weights on the edge (Fig. 6). In Fig. 6, $V=V_{1} \cup V_{2} \cup V_{3}$, they do not intersect each other, and $V_{1}=\left\{v_{l i} \mid i=1,2, \ldots, m\right\}$ represents a set of candidate energy stations and energy storage centers, $V_{2}=\left\{v_{2 j} \mid j=1,2, \ldots, n\right\}$ represents a set of road network nodes (such as intersection points, inflection points, access points, etc.), $V_{3}=\left\{v_{3 k} \mid k=1\right.$, $2, \ldots, q\}$ represents the load zone set; $E=\left\{e\left(v, v^{\prime}\right) \mid v\right.$, $\left.v^{\prime} \in V\right\}$ represents the case of direct connectivity between vertices; and $W=\left\{D(e)=D_{v, v^{\prime}} \mid e\left(v, v^{\prime}\right) \in E\right\}$ represents the weight set of edge $e$, in this paper, defined as energy distance, representing the pipeline cost including construction cost and maintenance cost.

In the nodes in Fig. 6, some nodes are selected as candidate nodes for energy stations and energy storage centers, which satisfy the optimal path between nodes. Furthermore, we should determine several points as the location of energy stations in these points. This belongs to the $P$-median problem of graph network theory, that is, we need to select the most satisfactory site on a given network map so that the total distance between the selected address based on the service requirement and the location of each service object can be minimized. It can be described as finding a subset $P$ from a node set $V$ in a connected map of a given $G=(V, E)$, and the number of elements of the subset is $|P|$, the sum of

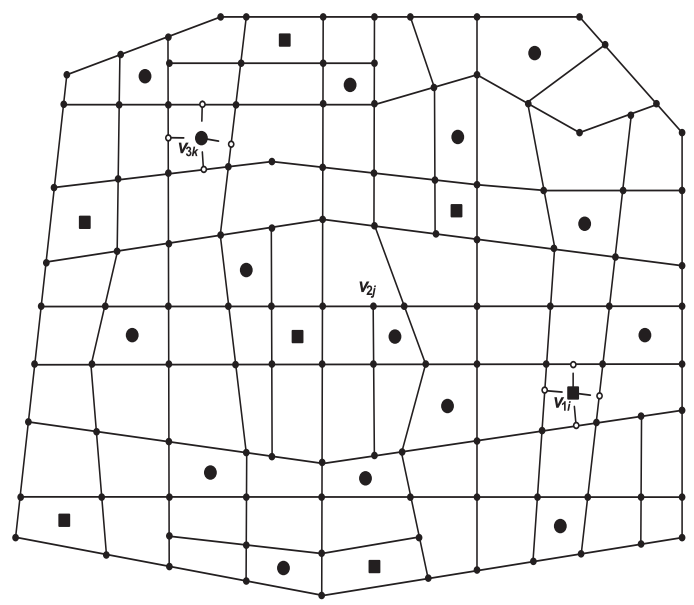

Fig. 6. RDES “station-network" diagram. 
the distance from the vertex set $V$ - $P$ to the nearest vertex in $P$ is the smallest. In RDES station-network map $G$, if there is a vertex set $P$ in $V_{1}$, it makes the sum of all vertices to the set $P$ in $V_{3}$ the minimum, then the set $P$ is called the $P$-median of the map. The solution of $P$-median is actually to find out the best combination that can be used as the energy station and its pipe network layout. It is worth noting that the layout of the pipe network in the RDES station-network map $G$ is not only the minimum distance between the single energy station node and the load node, but also the optimal path direction. As shown in Fig. 6, there are four access directions for the $v_{3 k}$ pipe network in the load area, which is given by dashed lines in the diagram. How to determine the optimal access direction of the pipe network also needs to be optimized.

\section{'Station-network' Layout Model of RDES}

\section{A. Definition of energy distance}

In station-network map $G=(V, E, W), \forall v, v^{\prime} \in V$, and $v \neq v^{\prime}$, the annual cost of route from the vertex $v$ to vertex $v$ ' can be represented by energy distance $D$ :

$$
D_{v, v^{\prime}}=C_{o}^{P L} \frac{r(1+r)^{L}}{(1+r)^{L}-1}+C_{f}^{P L}+C_{w}^{P L}+C_{m}^{P L}
$$

...where $P L$ represents pipeline, $r$ represents interest rate, and $L$ represents pipeline life.

Pipeline initial investment $C_{o}^{P L}$, annual operating cost of circulating water pump $\stackrel{o}{C}_{f}^{P L}$, cooling (heating) loss cost of water conveyance pipeline $C_{w}{ }^{P L}$, and annual depreciation and maintenance costs for pipelines $C_{m}{ }^{P L}$ can all be calculated by specific formulas [43]. The initial investment of pipeline includes all the investment of pipeline construction, such as pipe material, pipe accessories, heat preservation and construction, etc. The calculation formula is:

$$
C_{o}^{P L}=\sum_{i=1}^{K-1} C\left(d_{i}\right) l_{i}
$$

...where $C_{o}{ }^{P L}$ represents initial investment in the pipeline (yuan), $d_{i}$ represents the diameter of pipe section $i(\mathrm{~m}), l_{i}$ represents the length of pipe section $i(\mathrm{~m}), K$ represents the number of pipeline nodes, $C\left(d_{i}\right)$ represents unit cost of pipe section $i$ (yuan $/ \mathrm{m})$, and .

The formula for calculating the power charge of circulating water pump is:

$$
C_{f}^{P L}=\frac{P_{p} \times F_{p}}{\eta_{p}} T_{p} C_{e} \times 10^{-7}
$$

...where $C_{f}^{P L}$ represents the annual operating cost of the circulating pump (yuan), $F_{p}$ denotes the design flow of circulating water pump $\left(\mathrm{m}^{3} / \mathrm{s}\right), P_{p}$ represents the working pressure of a circulating pump $(\mathrm{Pa}), C_{e}$ represents the price of electricity (yuan/kW•h), $\eta_{p}$ represents the electromechanical efficiency of the pump, and $T_{p}$ represents the maximum annual working time of the circulating pump (h).

The formula for calculating the cost of cooling (heating) loss of the water conveyance pipeline is as follows:

$$
C_{w}^{P L}=\sum_{i=1}^{K-1} \frac{4 \pi \lambda l_{i} t_{c} T_{p} C_{e}}{\ln \frac{d_{i}+2 \delta_{i}+\delta_{t i}}{d_{i}+2 \delta_{i}} \times \operatorname{COP} \times 10^{7}}
$$

...where represents the cost of cooling (heating) loss in the pipeline (yuan); $\lambda$ represents the thermal conductivity of the insulating material, $\mathrm{W} /\left(\mathrm{m} \cdot{ }^{\circ} \mathrm{C}\right) ; t_{c}$ represents the average temperature difference between the inside and outside of the pipeline $\left({ }^{\circ} \mathrm{C}\right) ; \delta_{i}$ represents the thickness of the pipe $(\mathrm{m}) ; \delta_{t i}$ represents the thickness of the insulation layer of the pipeline (m); and COP represents the energy efficiency ratio of the system.

The formula for calculating the depreciation and maintenance costs of the pipeline is:

$$
C_{m}^{P L}=\left(\mu_{1}^{P L}+\mu_{2}^{P L}\right) C_{o}^{P L}
$$

...where $C_{m}{ }^{P L}$ represents the annual depreciation and maintenance costs of the pipeline (yuan); $\mu_{1}{ }^{P L}$ represents depreciation rate; and $\mu_{2}^{P L}$ represents the proportional factor for maintenance costs.

B. The median point in the station-network map based on energy distance

In the station-network map, $G=(V, E, W), \forall v \in$ $V_{l}, \forall \mathrm{v}^{\prime} \in V_{3}$, and $v \neq v^{\prime}, D_{v, v^{\prime}}^{\min }$ represents the minimum energy distance from the energy station $\mathrm{v}$ to the load region $v^{\prime}, S(v)$ represents the total cost, which is equal to the sum of all the products of the minimum energy distance from $v$ to each $v^{\prime}$ and the load demand of $v^{\prime}$, and plus the total cost of the initial investment of the energy station, which based on energy station to provide load demand service. That is:

$$
S(v)=C_{v}^{E S}+\sum_{\forall v^{\prime} \in V_{3}} D_{v, v^{\prime}}^{\min } Q_{v^{\prime}}
$$

In this case, vertex $z$ in which $S(v)$ takes the minimum value in all $v$ is called the median point of map $G$, which can be expressed as:

$$
S(z)=\operatorname{minS}(v), \forall v \in V_{1}
$$

...where a subgraph consisting of the shortest path between the minimum point $z$ of $S(v)$ and all $v^{\prime}$ is called the minimum spanning tree of $z$ relative to $V_{3}$.

Annual cost of energy station construction and maintenance, the formula can be expressed as:

$$
C_{v}^{E S}=C_{o}^{E S} \frac{r(1+r)^{L}}{(1+r)^{L}-1}+C_{m}^{E S}
$$


(1) Initial investment cost of energy station.

The initial investment of energy station includes civil construction cost, equipment investment and installation cost. In this paper, the calculation formula of the initial investment cost of the energy station is obtained by nonlinear least square fitting according to the capacity of the equipment, which is based on the analysis of the data of the actual engineering projects and related industries in China. The formula is:

$$
C_{o}^{E S}=\left[2.188 \times\left(\frac{V^{E S} C^{E S}}{10^{7}}\right)^{0.9198}+27.54\right] \times 10^{7}
$$

...where $C_{o}^{E S}$ represents the initial investment of the energy station (yuan); $V^{E S}$ represents the capacity of the device, $\mathrm{kW} ; C^{E S}$ represents the unit capacity investment cost of the equipment (yuan $/ \mathrm{kW}$ ), and assume that the investment in all supporting equipment has been converted.

(2) Annual maintenance and management costs of energy stations.

The annual maintenance and management costs of the energy station mainly include labour and maintenance costs, which can be calculated as follows:

$$
C_{m}^{E S}=\left(\mu_{1}+\mu_{2}\right) C_{o}^{E S}
$$

...where $C_{m}{ }^{E S}$ represents the cost of annual maintenance management (yuan); $\mu_{1}$ represents the proportional factor of labor costs; and $\mu_{2}$ represents the maintenance cost proportional factor.

C. $P$-median model based on energy distance

A subset $P$ is found in the candidate energy station set $V_{1}$ of RDES station-network map $G$ to serve the load demand points in the load zone set $V_{3}$. In this way, the sum of all the products of the minimum energy distance from the selected $|P|$ energy stations to the total load area and the load demand is minimized. Therefore, the model can be expressed as solving set $P\left\{v / v \in V_{1\}}\right.$, that is:

$$
f(P)=\min \sum_{\forall v \in X} S(v), \forall X \subset V_{1}
$$

The following conditions are met:

$$
\begin{gathered}
S\left(v_{i}\right)=C_{v_{i}}^{E S}+\sum_{\forall v_{i}^{\prime} \in V_{3}^{i}} D_{v_{i}, v_{i}^{\prime}}^{\min } Q_{v_{i}^{\prime}}, \\
\forall v_{i} \in X, \quad i=1,2, \ldots,|X| \\
V_{3}^{i} \subset V_{3}, \quad \bigcup_{i=1}^{|X|} V_{3}^{i}=V_{3} \\
\forall v_{i}, v_{j} \in X, \quad v_{i} \neq v_{j}, V_{3}^{i} \cap V_{3}^{j}=\emptyset
\end{gathered}
$$

The formula (42) indicates that in all subsets $X$ of $V_{1}$, $P$-median is the set $\mathrm{X}$ which minimizes the sum of $S(v)$. The realization of $S(v)$ is given by formula (43), and the subgraph formed by the minimum point $v_{i}$ of the sum of $S(v)$ and the shortest path between all $v_{i}^{\prime}$ in $V_{3}^{\prime}$ is called the minimum spanning tree of $v_{i}$ relative to $V_{3}^{\prime}$. Formula (44) indicates that all load areas are served by energy stations and formula (45) indicates that each load area can only be served by one energy station.

\section{Addressing and Network Layout Algorithm of RDES}

The main algorithms for solving the $P$-median problem are Lagrangian relaxation algorithm [44], genetic algorithm [45], Tabu search algorithm [46] and so on. In the RDES station-network map, due to the load nodes that are determined and the site selection of the energy station and the energy storage center is discrete and countable, the candidate solution space for site selection in a limited area is countable. Therefore, this paper proposes an RDES addressing and network layout algorithm based on energy distance, which not only traverses all feasible solutions in solution set space, but also determines that the obtained solution must be the optimal solution. It also avoids the possible sub-optimal solutions obtained by genetic algorithms. While the energy site is being determined, the algorithm will also give the optimal number of energy stations in the area, the optimal distribution path of energy stations and load distribution networks, and further give the location of the energy storage center. The procedure of addressing and network layout is shown in Fig. 7.

The specific process of the algorithm is as follows:

For station-network map $G=(V, E, W)$, we can assume that $X$ is a subset of $V_{1}, X \subset V_{1}, k=|X|$ represents the number of elements in the set $X$, and $k=1,2, \ldots, m$, $m$ is the number of elements of $V_{l}$. represents a set of $k$ elements. $P^{k}\left(V_{1}\right)$ represents a subset of the power set $V_{1}$, which consists of the subset of $V_{1}$ that contains only $k$ elements.

Initially, let $k=1$, the set of median points $P=\varphi$, economic cost $f(P)=0$, update the flag variable, flag $=0$.

Step 1: The minimum energy distance matrix $M$ between the vertices of map $G$ is established by using the Floyd shortest path calculation method:

$$
\begin{aligned}
& M\left(d_{v_{i} v_{j}}\right)=\left[\begin{array}{ccc}
d_{v_{1} v_{1}} & \cdots & d_{v_{1} v_{j}} \\
\vdots & d_{v_{i} v_{j}} & \vdots \\
d_{v_{j} v_{1}} & \cdots & d_{v_{j} v_{J}}
\end{array}\right]_{J \times J}, \\
& i, j=1,2, \ldots, J, \quad J=|V|=m+n+q
\end{aligned}
$$

...and,

$$
d_{v_{i} v_{j}}=\left\{\begin{array}{cl}
0 & v_{i}=v_{j} \\
D(e) & , \quad \exists e\left(v_{i}, v_{j}\right) \\
\min D_{v_{i} v_{j}} & \text { other }
\end{array}\right.
$$




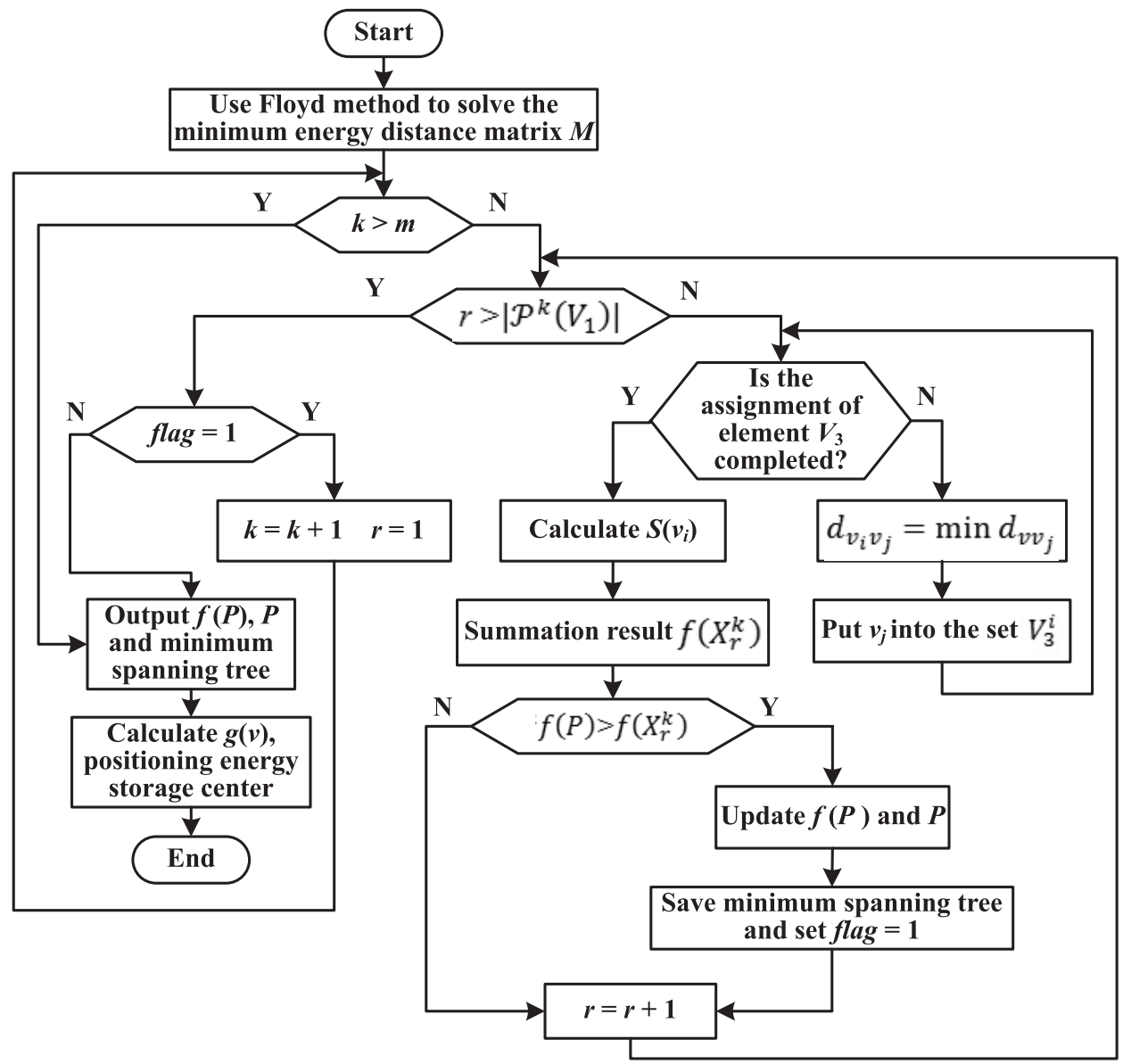

Fig. 7. Flow chart of addressing and network layout algorithm.

Step 2: If $k>m$, jump to step 8 , otherwise, execute step 3;

Step 3: If $r>\mid P^{k}\left(V_{1}\right)$, skip to step 7 when flag $=1$, otherwise, step 8 is executed. If $r \leq \mid P^{k}\left(V_{1}\right)$, then for all $\mathrm{v} \in X_{r}^{k}$ given $v_{j} \in V_{3}$, if $d_{v_{v} v_{j}}=\min d_{v v_{j}}$, put $v_{j}$ in the set $V_{3}^{i}$, repeat this process until all the elements in $V_{3}$ are allocated.

Step 4: For all $v_{i} \in X_{r}^{k}$, calculate $S\left(v_{i}\right)$, that is,

$$
S\left(v_{i}\right)=C_{v_{i}}^{E S}+\sum_{\forall v_{j} \in V_{3}^{i}} d_{v_{i} v_{j}} Q_{v_{j}}
$$

Then sum up, and get:

$$
f\left(X_{r}^{k}\right)=\sum_{\forall v_{i} \in X_{r}^{k}} S\left(v_{i}\right)
$$

Step 5: If $f(P)>f\left(X_{r}^{k}\right)$, update $f(P)$ and $P$, that is, $f(P)=f\left(X_{r}^{k}\right), P=X_{r}^{k}$, and holds all the minimum spanning trees from vertices to $V_{3}$ in the set $X_{r}^{k}$, and flag $=1$.

Step 6: $r=r+1$, go to step 3;

Step 7: $k=k+1, r=1$, go to step 2;

Step 8: The minimum economic cost, the set of median points $P$ and the corresponding set of minimum spanning trees are output. Among them, the median points of $P$ is the location of the planned energy station, the number of which is $|P|$, the minimum spanning tree is the scheme of pipe network layout.

Step 9: For all remaining candidate vertices $v_{i}$ after the removal of $P$-median points in $V_{1}$, and find out the point $v$ that is the smallest sum of the energy distance to all the median points $v_{j}$ in $P$, that is, calculate $g(v)$ :

$$
g(v)=\min \sum_{\forall v_{j} \in P} d_{v_{i} v_{j}}, \forall v_{i} \in V_{1}-P
$$

$v$ is regarded as the location of energy storage center, and the shortest path between $\mathrm{v}$ and $P$ is regarded as the pipeline direction between energy storage center and energy station.

At this point, the algorithm ends.

\section{Results and Discussion}

\section{RDES Planning of an Ecological Town in China}

The ecological town is a new low-carbon and green district planned by the provincial capital city of central China. The core road network area is $2.09 \mathrm{~km}^{2}$. 


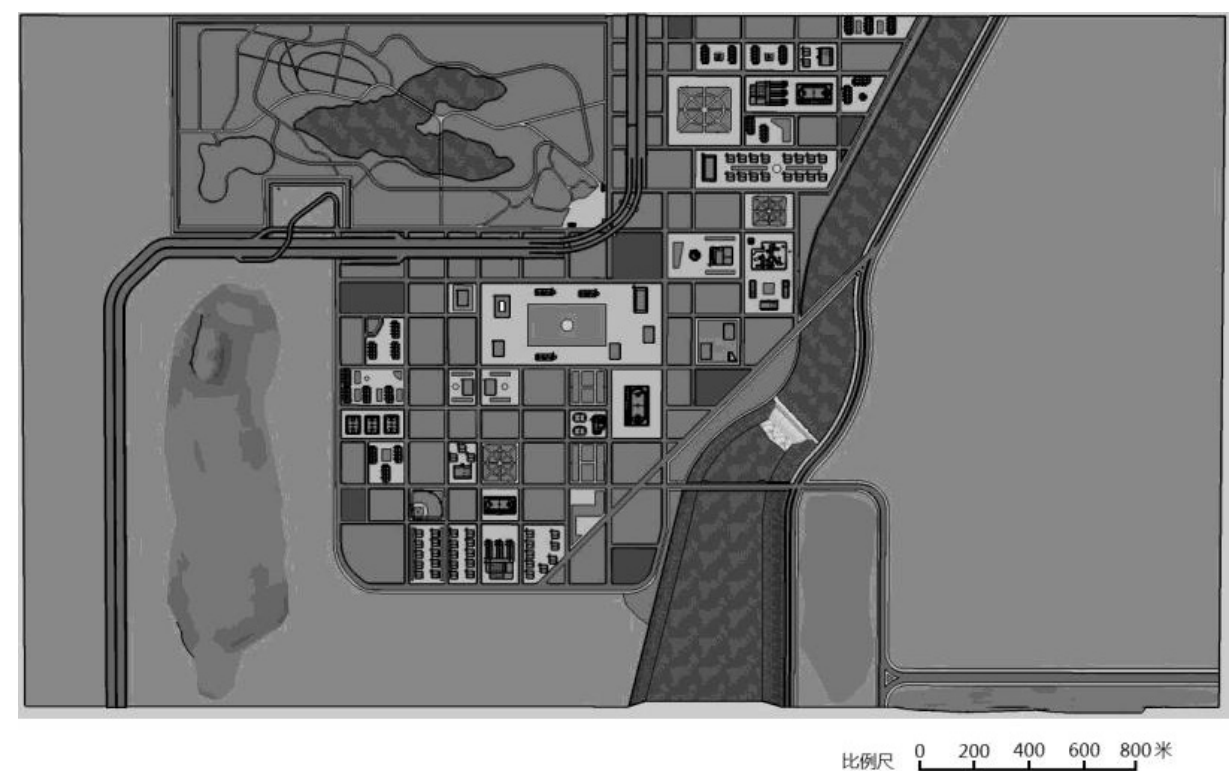

Fig. 8. Planning renderings of the case area.

The latitude and longitude coordinates of the area are as follows: latitude 36.99/37.01 and longitude 117.20, 117.23. The planning renderings of the case area are shown in Fig. 8.

The planning area is centered on low carbon, which is developing from green building and green community to green area through the concept of green energy. In order to meet the needs of a regional population, work and spirit, the region constructs a service network, including infrastructure services, which covers the whole area of the new district and provides convenient services to residents with the concept of small-scale block design. Three small-scale residential concentration areas are planned in the area, which are located in the north, south and west of the region, respectively. The regional center is mainly office, hotel, business, medical, old-age care, school and other services, educational institutions follow the ecological, convenient layout. The basic information of the regional planning buildings is shown in Table 1.
The climate of the planning area belongs to the typical continental monsoon climate, the seasonal variation of the demand for cooling and heating load is strong, and the energy demand is complex, which is the key area of energy savings and emissions reduction and energy low-carbon development in China. The advantage of RDES cascade energy utilization is conducive to achieving the energy expectation of green and low-carbon in the region.

\section{Regional Load Forecasting}

According to the different types of buildings in the area, we use three-dimensional modeling software SketchUp Pro to build individual building models. The apartment, office and supermarket models are shown in Fig. 9. Then OpenStudio 1.13.0 graphical interface is used to call Energyplus load simulation software to predict the cooling, heating and power load of a single building.

Table 1. List of buildings in the case area.

\begin{tabular}{|c|c|c|c|c|c|}
\hline Building & Quantity & Total area $\left(\mathrm{m}^{2}\right)$ & Building & Quantity & Total area $\left(\mathrm{m}^{2}\right)$ \\
\hline Administrative office building & 2 & 21766.92 & Primary school & 1 & 7109.38 \\
\hline Commercial ffice building & 6 & 108835 & Middle school & 1 & 13627.29 \\
\hline Library & 1 & 7255.67 & Kindergarten & 1 & 3265.27 \\
\hline Hotels & 3 & 24081.54 & Hospital & 1 & 20173.98 \\
\hline Commercial Golden Street & 1 & 36703.84 & Supermarket & 2 & 4587.98 \\
\hline Commercial complex & 2 & 113745.62 & Apartment & 5 & 35462 \\
\hline Restaurant & 5 & 2555.75 & Western-style & 16 & 127663.2 \\
\hline hursing home & 1 & 3804.01 & Villa & 29 & 7424 \\
\hline
\end{tabular}


a)

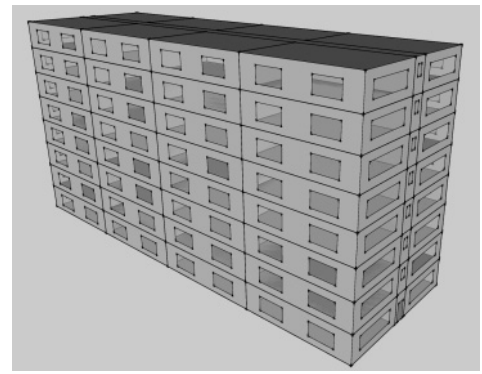

b)

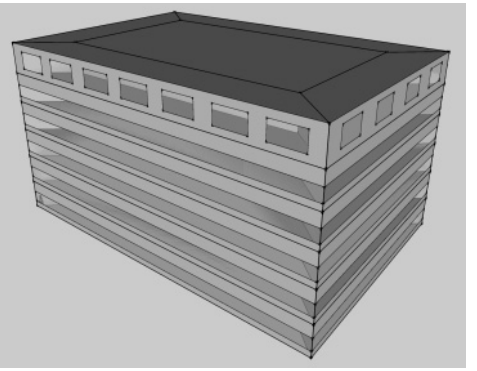

c)

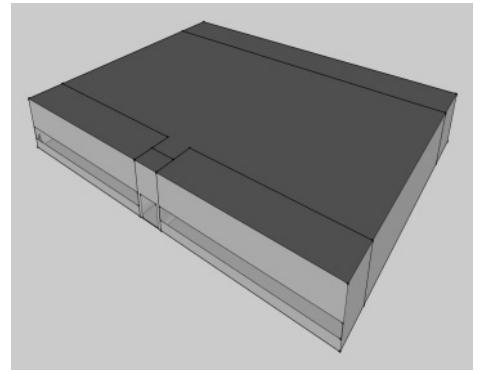

Fig. 9. SketchUp model diagram of single simulated building: a) Apartment building model the first panel, b) Office building model, c) Commercial supermarket model.

EnergyPlus provides meteorological data for several countries, including China, CSWD (special meteorological data set for building thermal environment analysis in China) provides the meteorological data of 270 regions in China, and provides the basis for the setting of dynamic simulation meteorological parameters. According to the requirements for building energy conservation of public buildings and residential buildings [47, 48], which is proposed by the Ministry of Housing and local governments in China (thermal parameters of enclosure structure and interior design parameters of the buildings are shown in Tables 2 and 3).

The average daily load of cooling, heating and power in the region is shown in Fig. 10. Considering the overall energy planning of the region, the load demand cannot simply be superimposed. In this paper, we adopted a calculation model with coefficient of simultaneous use [49], and finally got the regional overall load demand forecast results: total cooling load $2.13739 \times 10^{7} \mathrm{kWh}$, total heat load $1.2532 \times 10^{7} \mathrm{kWh}$, and total power load $5.37435 \times 10^{7} \mathrm{kWh}$.

\section{Decision-Making and Capacity Optimization of RDES}

\section{A. Decision optimization}

Based on the investigation of social economic conditions, air environment, resource conditions, preferential policies and other factors in the region, the RDES upper level optimization decision is made by the rules $(I F \ldots T H E N \ldots)$ and reasoning process formed by expert experience and knowledge.

(1) Socio-economic environment.

In 2016, GDP of the province where the town is located grew 7.6 percent over the previous year, making it the third largest economy in China, and GDP ranked 21 among the top 100 cities in 2016. In 2016, the urbanization rate of the city was 69.46 percent, and the per capita disposable income of urban residents was 43052 yuan. The average housing floor area of urban residents exceeded 37.3 square meters, and the average growth rate of power consumption durable consumer goods was 3 percent, and the growth rate of air conditioners reached $4.1 \%$. RDES planning has better social environment and economic conditions.

Table 2. Thermal parameters of enclosure structure.

\begin{tabular}{|c|c|c|c|c|}
\hline & \multirow{3}{*}{ Enclosure structure position } & \multicolumn{3}{|c|}{$\begin{array}{l}\text { Heat transfer coefficient } \\
\qquad\left(\mathrm{W} /\left(\mathrm{m}^{2} \cdot \mathrm{K}\right)\right)\end{array}$} \\
\hline & & \multirow{2}{*}{$\begin{array}{c}\text { Residential } \\
\text { building }\end{array}$} & \multicolumn{2}{|c|}{ Public buildings (Category A standard) } \\
\hline & & & $\begin{array}{c}\text { Shape } \\
\text { coefficient } \leq 0.3\end{array}$ & $\begin{array}{c}0.3<\text { Shape } \\
\text { coeffcient } \leq 0.5\end{array}$ \\
\hline & Roof & $\leq 0.4$ & $\leq 0.45$ & \\
\hline & External walls (including non-transparent curtain walls) & $\leq 0.45$ & $\leq 0.50$ & $\leq 0.45$ \\
\hline & Overhead or overhanging floor & $\leq 0.45$ & $\leq 0.50$ & $\leq 0.45$ \\
\hline & Floor of Underground Garage and heating Room & $\leq 0.50$ & $\leq 1.0$ & $\leq 1.0$ \\
\hline & Window wall ratio $\leq 0.2$ & $\leq 2.5$ & $\leq 3.0$ & $\leq 2.8$ \\
\hline \multirow{5}{*}{$\begin{array}{c}\text { Single } \\
\text { Towards } \\
\text { Outer } \\
\text { window }\end{array}$} & $0.2<$ Window wall ratio $\leq 0.3$ & $\leq 2.3$ & $\leq 2.7$ & $\leq 2.5$ \\
\hline & $0.3<$ Window wall ratio $\leq 0.4$ & $\leq 2.0$ & $\leq 2.4$ & $\leq 2.2$ \\
\hline & $0.4<$ Window wall ratio $\leq 0.5$ & $\leq 1.8$ & $\leq 2.2$ & $\leq 1.9$ \\
\hline & $0.5<$ Window wall ratio $\leq 0.6$ & - & $\leq 2.0$ & $\leq 1.7$ \\
\hline & $0.6<$ Window wall ratio $\leq 0.7$ & - & $\leq 1.9$ & $\leq 1.7$ \\
\hline
\end{tabular}


Table 3. Indoor design parameters and electric power index of lighting electrical equipment.

\begin{tabular}{|c|c|c|c|c|c|c|c|c|}
\hline & \multicolumn{2}{|c|}{$\begin{array}{c}\text { Summer, } \\
\text { transition season }\end{array}$} & \multicolumn{2}{c|}{ Winter } & \multicolumn{4}{c|}{ Design parameters } \\
\hline $\begin{array}{c}\text { Building. } \\
\text { Type }\end{array}$ & $\begin{array}{c}\text { Temperature } \\
\left({ }^{\circ} \mathrm{C}\right)\end{array}$ & $\begin{array}{c}\text { Relative } \\
\text { humidity } \\
(\%)\end{array}$ & $\begin{array}{c}\text { Temperature } \\
\left({ }^{\circ} \mathrm{C}\right)\end{array}$ & $\begin{array}{c}\text { Relative } \\
\text { humidity } \\
(\%)\end{array}$ & $\begin{array}{c}\text { Fresh air } \\
\text { volume } \\
\left(\mathrm{m}^{3} / \lambda\right)\end{array}$ & $\begin{array}{c}\text { Lighting } \\
\text { power density } \\
\left(\mathrm{W} / \mathrm{m}^{2}\right)\end{array}$ & $\begin{array}{c}\text { Personnel } \\
\text { Density } \\
\left(\mathrm{m}^{2} / \lambda\right)\end{array}$ & $\begin{array}{c}\text { Equipment } \\
\text { power } \\
\left(\mathrm{W} / \mathrm{m}^{2}\right)\end{array}$ \\
\hline Residence & $26 \sim 28$ & $45 \sim 65$ & $18 \sim 22$ & $40 \sim 60$ & 25 & 9 & 10 & 5 \\
\hline Office & $24 \sim 26$ & $45 \sim 65$ & $18 \sim 20$ & $40 \sim 60$ & 30 & 9 & 10 & 15 \\
\hline Business & $24 \sim 28$ & $45 \sim 65$ & $16 \sim 18$ & $40 \sim 60$ & 30 & 10 & 8 & 15 \\
\hline Hotel & $22 \sim 26$ & $45 \sim 65$ & $18 \sim 24$ & $40 \sim 60$ & 40 & 7 & 25 & 15 \\
\hline School & $24 \sim 26$ & $45 \sim 65$ & $18 \sim 20$ & $40 \sim 60$ & 30 & 9 & 6 & 5 \\
\hline Hospital & $24 \sim 26$ & $45 \sim 65$ & $18 \sim 20$ & $40 \sim 60$ & 30 & 9 & 8 & 20 \\
\hline
\end{tabular}

(2) Regional resource condition.

The town area is not only located on the main gas pipeline from Zhongyuan Oilfield to Qingdao, but also has two vertical natural gas pipelines, and the natural gas supply in the region is stable. In addition, the sunshine hours of the whole year in the region are more than 2500 , which belongs to an area with abundant potential for solar energy resources in China. The time of annual average wind speed of which is more than 3 $\mathrm{m} / \mathrm{s}$ in the region accounts for about half of the whole year, which belongs to the available area of wind energy resources in China. In 2016, the total installed capacity of the new energy generation in the cities of the planning area accounted for $10.5 \%$ of the total installed capacity of the whole city, of which the proportion of solar energy and wind power generation reached nearly $50 \%$. The regional renewable resource endowment meets the planning conditions.

(3) Regional environment.

In 2011, the per capita carbon dioxide emissions of the province where the town is located reached 10 tons per person, ranking 8th in China, and the density of carbon dioxide emissions exceeded 6000 tons per $\mathrm{km}^{2}$, ranking 4th in the country [50]. In 2016, the average annual concentration of PM2.5 in the city was $75.6 \mathrm{micrograms} / \mathrm{cubic}$ meter, and the air quality was the reciprocal ninth among the 74 major cities monitored in China, and the air quality situation was grim. In order to solve the asymmetric problem of economic and environmental development in this region, the government proposed that the planning of energy systems should not only consider the economy, but also realize energy savings and emissions reduction.

(4) Regional support policy.

The province where the town is located has formulated "the $13^{\text {th }}$ Five-Year Plan for Solar Energy" to vigorously promote the development of distributed photovoltaic power generation. In addition, it set a goal of saving 3.3 million tons of standard coal for solar power generation by 2020. In 2016, in order to support the development of renewable energy, the grid-connected distributed photovoltaic power generation project increased provincial subsidies of 0.05 yuan per kilowatt-hour on the basis of national electricity price subsidies. The project of wind power generation shall be subsidized by 0.02 yuan per kilowatt-hour on the basis of the national benchmark electricity price. The highest feed-in tariff of natural gas CHP generation projects can be increased by 0.35 yuan at the highest level on the basis of benchmarking coal-fired power generation tariffs per $\mathrm{kWh}$ in the same period.

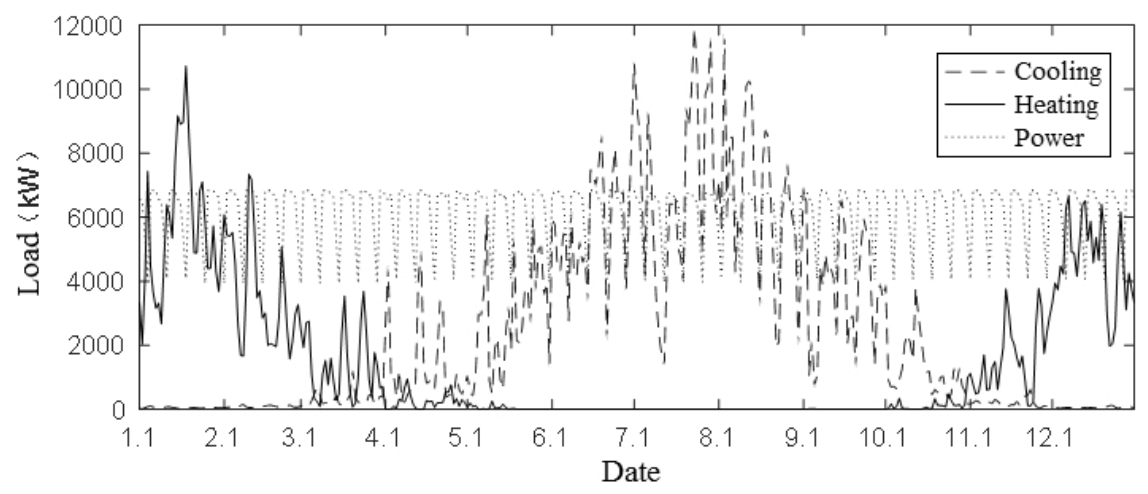

Fig. 10. Daily average load of the region. 
(5) Equipment factor.

Based on the analysis of the social development conditions, source endowment and preferential policies in the region, the types of RDES equipment that can be selected in the region are as follows: triple supply equipment with natural gas as input energy, wind power generation equipment and photovoltaic power generation equipment. At the end of 2016, a high-pressure gas pipeline was been built in this area, the highest pressure grade is $4.0 \mathrm{Mpa}$. The annual capacity of natural gas transmission and distribution is further enhanced. Therefore, the gas turbine and internal combustion engine can be used as the main engine of the joint supply system. In order to improve the efficiency of energy utilization, the equipment of the energy system should be equipped with absorption refrigerators, power storage, heating storage, cooling storage devices, and supplementary combustion boilers, etc. in order to achieve the system connectivity flexible supply capacity. B. System capacity optimization

We adopt the decision optimization result and the RDES capacity optimization method, take the economic cost and the environmental protection cost as the system capacity optimization goal, and adopt the network connection and network operation mode encouraged by the region, and set the upper limit of the equipment capacity to $10000 \mathrm{~kW}$, set the population size of the NSGA-II to 50, after iterating 100 times, the algorithm eventually converges to a better optimal leading edge distribution, as shown in Fig. 11. With the reference to expert advice and the regional advance development plan, the RDES capacity allocation scheme for the town is as follows: minimum economic cost $7.58 \times 107$ yuan, minimum carbon dioxide emissions $1.43 \times 1011$; capacity of drive equipment of natural gas type $I_{V g d r l}, 564.84 \mathrm{~kW}$; capacity of solar power system $V_{P V}, 7776.86 \mathrm{~kW}$; rated

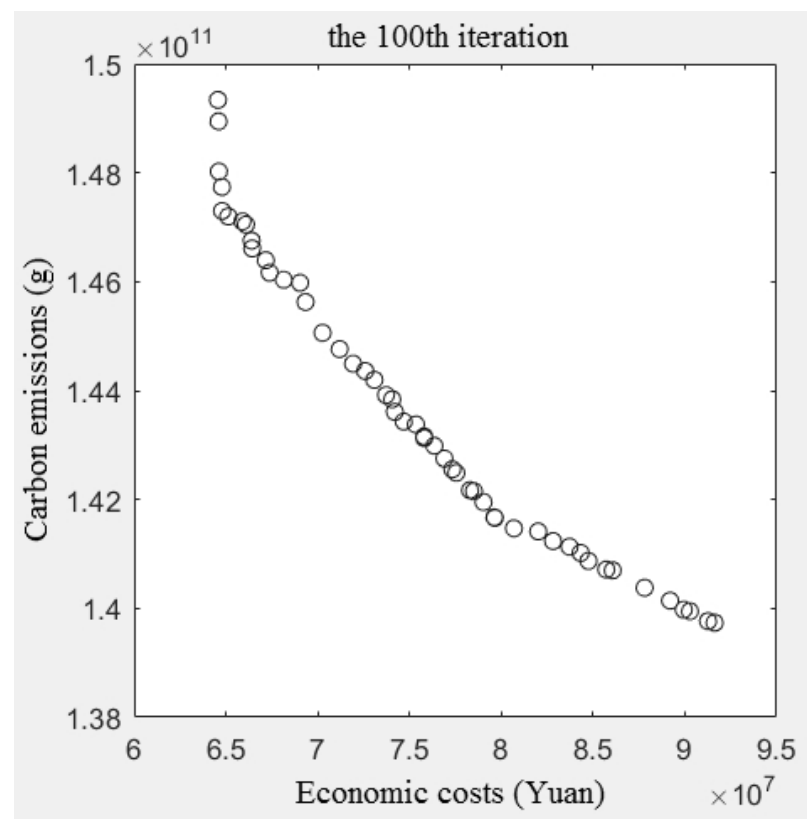

Fig. 11. Optimized process control of RDES system capacity. output power of wind power system $V_{W T}, 0$; capacity of heat storage unit $V_{s h}, 8216.6 \mathrm{~kW}$; capacity of cooling storage unit $V_{s c}, 9441.47 \mathrm{~kW}$; capacity of power storage unit $V, 3702.08 \mathrm{~kW}$; electric refrigeration ratio $\delta$, 0.906094 .

\section{Layout Optimization of RDES 'Station Network'}

On the basis of RDES decision and capacity optimization, the planning and design of energy station and pipe network layout in the region are carried out. Because the network of the ecological town is still in the planning stage, it cannot be directly accessed by OpenStreetMap, so the regional longitude and latitude coordinates are registered in OpenStreetMap, and you can extract the network skeleton from JOSM, as shown in Fig. 12.

According to the skeleton map of regional road network extracted by JOSM, 7 locations can be selected, which form energy station and energy storage center,

a)

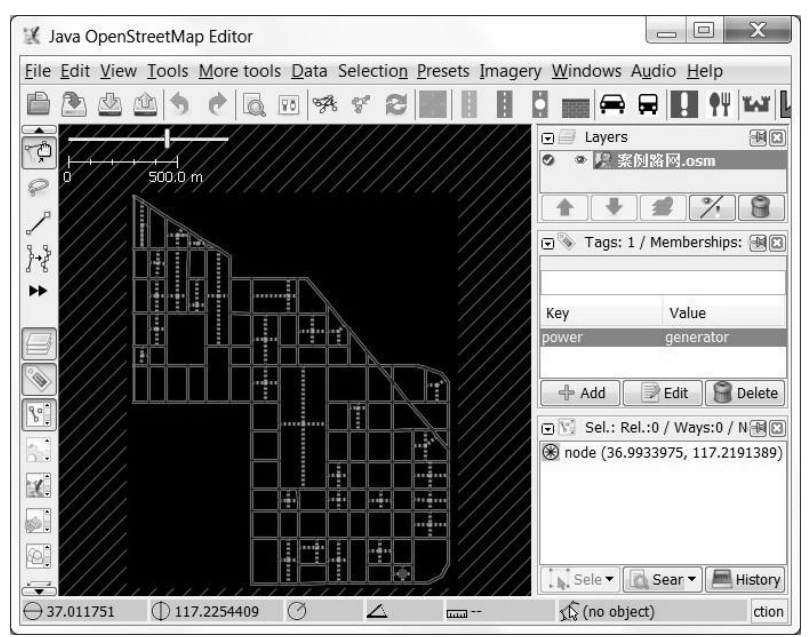

b)

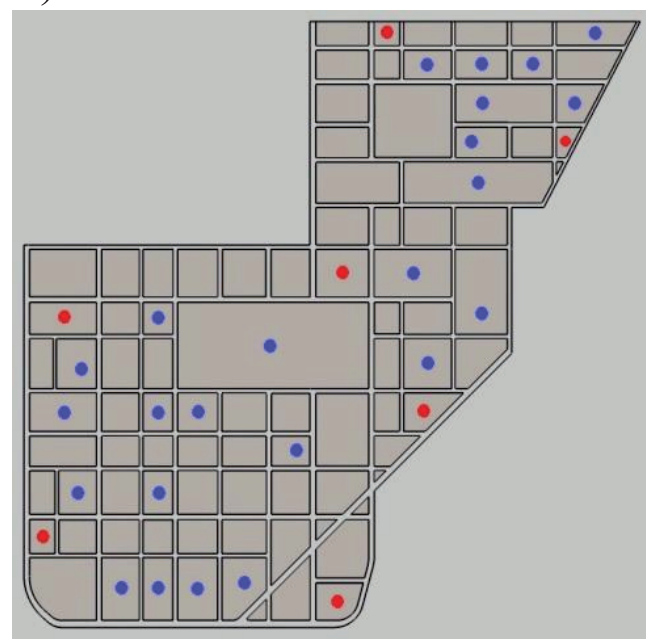

Fig. 12. a) Regional road network skeleton chart 1 and b) Regional node distribution chart. 
as shown in Figure 12(b). The red dot represents the candidate node for the energy station and the energy storage center, and the blue point represents the load area of the case area. By using the $P$-median model based on the energy distance and the addressing network algorithm, we can obtain the optimal layout of the energy station position, the energy storage center and the pipeline network trend in the planning area with the minimum energy distance. As seen in Figure 13 , the blue point represents the load center of the case area; the red point is the final 3 energy stations and their locations by using the $P$-median model based on the energy distance and the algorithm of the cooperative layout; the green line represents the layout of the optimal pipe network between the energy stations and the load centers, which realizes the minimum distance between all load centers and the energy stations set; the yellow point represents the energy storage center of the case area; the deep green line represents the path between the energy storage center and the established energy stations, with the minimum distance at this time. When the energy supply of a certain energy station is larger than the load demand, the excess energy will be stored in the energy storage center through the connected pipeline. When the energy supply of the energy station cannot meet load demand, it will be released and supplemented. The energy storage center acts as a buffer between energy stations, which promote the dynamic balance between supply and demand in the RDES and improve the reliability and energy efficiency of the system.

It can be seen that the layout of the pipe network has the characteristics of energy bus with many branches and multiple sources, and there is the possibility of reclosing the pipeline. In order to avoid the occurrence of multiline coexistence and reducing the cost, it can be combined with reclosing pipeline by increasing the diameter of the pipe.

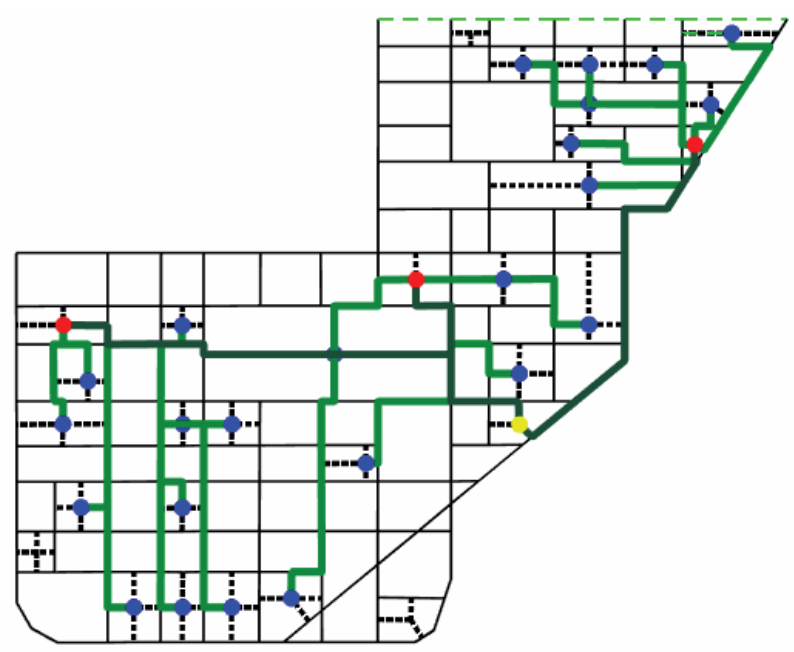

Fig. 13. Layout map of regional energy station, energy storage center and pipe network.

\section{Conclusions}

In this paper we studied the planning of a regional distributed energy system. According to the actual situation of China, a planning method for a regional distributed energy system is put forward. The feasibility and validity of the model and method are verified by taking a planned ecological town in China as an example. The following conclusions are obtained:

1) Under the deep integration of energy and information, we build an information and physical fusion model for RDES based on MAS, and energy management agent and routing agent undertake the scheduling and running tasks of the system in the future.

2) The dual-level optimization model of RDES based on decision and capacity optimization is constructed. The optimal decision level is determined by many factors such as social development, environment, resources and policies. The capacity optimization level is composed of system goals, system constraints and optimization algorithms.

3) An optimization method is proposed for the cooperative layout of source, network and load of RDES. This method not only determines the number and location of energy stations and location of energy storage center for RDES planning, but also provides the optimal path for an energy transmission network.

\section{Acknowledgements}

This work was supported by the National Social Science Foundation of China (17BGL252) and the Fundamental Research Funds for the Central Universities (17MS169).

\section{Conflict of Interest}

The authors declare no conflict of interest.

\section{References}

1. STEEMER K. Energy and the city: density, buildings and transport. Energy and Buildings, 35, 3, 2003.

2. TIAN W., WEI L., ZHU L., HE C., SUN Y., YANG S. Building energy analysis at urban scale. Building Energy Efficiency, 44, 59, 2016.

3. ADALBERTH K. Energy use during the life cycle of single-unit dwellings: examples. Building and Environment, 32, 321, 1997.

4. LIU D.L., LIU J.P, YANG L. Building energy consumption principia under climate change in China. Acta Energiae Solaris Sinica, 34, 439, 2013.

5. DAI Y.D., LV B., FENG C. China total energy consumption control and energy conservation during the $13^{\text {th }}$ five-year period. J. Beijing Inst. Tech. (Soc. Sci. Ed.), 17, 1, 2015.

6. JEREMY R. The Third Industrial Revolution. Publisher: Citic Press: Beijing, China, 46, 2012. 
7. IEA ECBCS Annex 49. Low energy systems for high performance buildings and communities. Available online: http://www. ecbcs. org/ annexes/annex49.htm. (accessed on 26 December 2017)

8. JIN M., FENG W., LIU P., MARNAY C., SPANOS C. MOD-DR: microgrid optimal dispatch with demand response. Applied Energy, 187, 758, 2017.

9. STIEL A., KAZACOS M.S. Feasibility study of energy storage systems in wind/diesel applications using the HOMER model. Applied Sciences, 2, 726, 2012.

10. MIRZAHOSSEINI A.H., TAHERI T. Environmental, technical and financial feasibility study of solar power plants by RETScreen, according to the targeting of energy subsidies in Iran. Renewable and Sustainable Energy Reviews, 16, 2806, 2012.

11. ZHOU N., MARNAY C., FIRESTONE R., et al. An analysis of the DER Adoption climate in Japan using optimization results for prototype buildings with U.S. comparisons. Energy and Buildings, 38, 1423, 2006.

12. KANNAN R. The Development and application of a temporal MARKAL energy system model using flexible time slicing. Applied Energy, 88, 2261, 2011.

13. ALVARADO D.C., ACHA S., SHAH N., MARKIDES C.N. A technology selection and opera-lion (tso) optimisation model for distributed energy systems: mathematical formulation and case study. Applied Energy, 180, 491, 2016.

14. JU L.W., TAN Z.F., LI H.H., TAN Q.K., YU X.B., SONG X.H. Multi-objective operation optimization and evaluation model for CCHP and renewable energy based hybrid energy system driven by distributed energy resources in China. Energy, 111, 322, 2016.

15. MENDES G., IOAKIMIDIS C., FERRAO P. On the planning and analysis of integrated community energy systems: a review and survey of available tools. Renewable \& Sustainable Energy Reviews, 15, 4836, 2011.

16. XU B.P., XU W.L. Approach and practice of regional energy planning under low carbon situation. HV\&AC, 42, 10, 2012.

17. LONG W.D. Smart micro energy network in green ecocommunities. HV\&AC, 43, 39, 2013.

18. LI J., ZHANG R.X., YANG H.M., SUN Z.Y., FENG X.M., QIAO B. Study on energy planning in green ecological city. Building Science, 31, 141, 2015.

19. BRUM M., ERICKSON P., JENKINS B., KORNBLUTH $\mathrm{K}$. A comparative study of district and individual energy systems providing electrical-based heating, cooling, and domestic hot water to a low-energy use residential community. Energy and Buildings, 92, 306, 2015.

20. OZUGUL M.D., CEKIC T.I., OZBAKIR A. The next wave of sustainable planning: green neighbourhood assessment systems. Int. J. Env. and Sus. Dev., 13, 109, 2014.

21. YANG Y.P. Distributed energy system. Bei Jing: Chemical Industry Press, 11, 2011.

22. HUA B., GONG J. Developing the SGTES centering on DES/CCHP. Building Science, 23, 5, 2007.

23. LONG W.D. Energy management and internet thinking in green ecological urban area. Con. Sci. Tech, 7, 28, 2015.

24. LONG W.D. Green winter olympics and national renewable energy demonstration area under the background of Zhangjiakou building energy planning. Con. Sci. Tech., 20, 26, 2015.

25. JENNINGS N.R., SYCARA K., WOOLDRIDGE M. A roadmap of agent research and development. Aut. Age. Multi-Agent Syst., 1, 7-38, 1998.
26. FALKE T., KRENGEL S., MEINERZHAGEN A.K., SCHNETTLER A. Multi-objective optimization and simulation model for the design of distributed energy systems. Applied Energy, 184, 1508, 2016.

27. REN H.B., WU Q., GAO W.J., ZHOU W.S. Optimal operation of a grid-connected hybrid pv/fuel cell/battery energy system for residential applications. Energy, 113, 702, 2016.

28. TAN X., WU Y., TSANG D.H.K. Pareto optimal operation of distributed battery energy storage systems for energy arbitrage under dynamic pricing. IEEE Trans. Par. Dis. Syst., 27, 2103, 2016.

29. YANG W.Y., ZHAO Y.R., LISO V., BRANDON N. Optimal design and operation of a syngas-fueled SOFC Micro-CHP system for residential applications in different climate zones in China. Energy and Buildings, 80, 613, 2014.

30. MAROUFMASHAT A., SATTARI S., ROSHANDEL R., FOWLER M.W. Multi-objective optimization for design and operation of distributed energy systems through the multi-energy hub network approach. Ind. Eng chem. Res., 55, 8950, 2016

31. ELTAMALY A.M., MOHAMED M.A. A novel design and optimization software for autonomous pv/wind/battery hybrid power systems. Math. Prob. Eng., 1, 2014.

32. CHEN J., WANG C.S., ZHAO B., ZHANG X.S. Economic operation optimization of a stand alone microgrid considering characteristics of energy storage system. Auto. Elec. Pow. Syst., 36, 25, 2012.

33. LIANG H., ZHANG F., LONG W.D. Optimization model of complementary district energy system based on multienergy-sources. HV\&AC, 42, 67, 2012.

34. WU X., WANG X.L., BIE Z.H., WANG J.X. Economic operation of microgrid with combined heat and power system. Elec. Pow. Auto. Equip., 33, 1, 2013.

35. YOKOYAMA R., ITO K. Effect of inlet air cooling by ice storage on unit sizing of a gas turbine cogeneration plant. J. Eng. Gas Tur. Pow., 126, 351, 2004.

36. XIAO X.Q., KAN W.M., YANG Y., ZHANG S.J., XIAO Y.H. Superstructure-based optimal planning of cogeneration systems with storage. Proc. CSEE, 32, 8, 2012.

37. DEB K., PRATAP A., AGARWAL S., MEYARIVAN T. A fast and elitist multi-objective genetic algorithm: NSGA-II. IEEE Trans. Evo. Com., 6, 182, 2002.

38. LI P.H., LOU Y.Y. An integer multi-objective optimization model and an enhanced non-dominated sorting genetic algorithm for contraflow scheduling problem. J. Cen. Sou. Uni., 22, 2399, 2015.

39. ZHU Z.J., WANG J., BALOCH M.H. Dynamic economic emission dispatch using modified NSGA-II. Elec. En. Syst., 26, 2684, 2016.

40. CHINESE D. Optimal size and layout planning for district heating and cooling networks with distributed generation options. Int. J. En. Sec. Man., 2, 385, 2008.

41. WEI H.R., DONG M. Based on the bi-level programming for distributed energy systems can build a model of network. China Min. Mag., 18, 108, 2009.

42. LI H.Q., ZHANG X.F., DONG W.J., ZHANG G.Q. Optimum research on cooling and heat transmission and distribution pipe network in smart grid. J. Eng. Therm., 35, 1275, 2014.

43. LONG W.D., BAI W., FAN R. Community Energy Planning for Built Environment in Low Carbon Cities. China Architecture and Building: Beijing, China, 284, 2012. 
44. AHKIN T. Lagrangian relaxation based approaches to capacitated hub-and-spoke network design problem. Eur. J. Oper. Res., 79, 501, 1994.

45. ALP O., ERKUT E., DREZNER Z. An efficient genetic algorithm for the p-median problem. Ann. Oper. Res., 122, 21, 2003.

46. CHEN J., REN Y., ZENG G. An improved multi-harmonic sine fitting algorithm based on tabusearch. Measurement, 59, 258, 2015.

47. Ministry of Housing and Urbar-Rural Development of the People's Republic of China. GB50189-2015 Energy Saving Design Standard for Public Buildings. China Construction Industry Press: Beijing, China, 15, 2015.
48. Ministry of Housing and Urbar-Rural Development of Shan Dong Province. DB37/5026-2014 Energy Saving Design Standard for Residential Buildings. China Building Materials Industry Press: Beijing, China, 3, 2015.

49. SU B., ZHAO K., ZHAO B.K. Cooling load forecasting and simultaneity usage coefficient determination of district cooling energy station. Chongqing Architecture, 13, 12, 2014.

50. OU Y.M. A Comparative Study on Chinese Provincial Carbon Emissions. PH.D. Dissertation, Huazhong University of Science and Technology, Wu Han, China, 2015. 